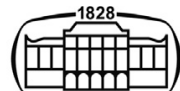

AKADÉMIAI KIADÓ

UNIVERSITY of DEBRECEN

\section{International Review of Applied Sciences and Engineering}

$12(2021) 3,238-256$

DOI:

$10.1556 / 1848.2021 .00264$

(c) 2021 The Author(s)

\title{
Assessment of RANS turbulence closure models for predicting airflow in neutral ABL over hilly terrain
}

ORIGINAL RESEARCH PAPER

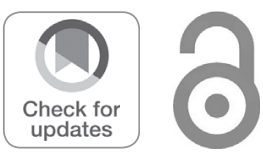

\author{
Amahjour Narjisse $^{1 *}$ and Khamlichi Abdellatif ${ }^{2}$ \\ ${ }^{1}$ Department of Physics, Faculty of Science Tetouan, University Abdelmalek Essaadi, 93030, Tetouan, \\ Morocco \\ ${ }^{2}$ Department TITM, National School of Applied Sciences at Tetouan, University Abdelmalek \\ Essaadi, 93030, Tetouan, Morocco
}

Received: February 23, 2021 • Accepted: April 3, 2021

Published online: May 20, 2021

\begin{abstract}
Implementing wind farms in heights of a hilly terrain where wind speed is expected to be large may be viewed as a means to increase wind energy production without occupying fertile lands. Micro sitting of a wind farm in these conditions can gain dramatically from CFD simulation of fluid flow in the ABL above complex topography. However, this issue still poses tough challenges regarding the turbulence model to be used and the way to operate the near wall treatment in the presence eventually of separation. In this work, prediction capacity of RANS turbulence models was studied for a typical hill under the assumption of steady state and incompressible airflow regime in neutral ABL. Two models were analyzed by using COMSOL Multiphysics software packages. These included standard $k-\varepsilon$, and shearstress transport $k-\omega$. The most up-to-date procedures dedicated to near wall treatment were applied along with refined closer coefficients adjusted for the particular case of ABL. Considering wind tunnel test data, performance of the previous models was discussed in terms of converging mesh, computational time, reattachment point position and propensity of the model to retrieve the right level of turbulence flow in conditions of neutral stratifications. Then, a numerical simulation of the turbulent airflow over two slopes shapes of the symmetry hill by the validation of the experimental data has been then carried out. Both turbulence models agree well with air-velocity tested windward of the hills H3 and H5. Therefore, it was found that the standard $k-\varepsilon$ model performs very well at the different positions of the low slope hill, and at the summit of a steep hill, but it over-predicts wind speed close to the wall, which requires an improvement of the near-wall treatment. However, the SSTK $-\omega$ model in neutral case of the ABL was given consistent simulation results with experimental data for prediction of the flow separation and recirculation region at the leeward side of a steep hill, whereas standard $k-\varepsilon$ model under the neutral condition and the SSTK $-\omega$ model by using standard coefficients were failed to predict accurately detailed characteristics of recirculation region process.
\end{abstract}

\section{KEYWORDS}

wind, neutral atmospheric boundary layer, hilly terrain, RANS, turbulence models

\section{INTRODUCTION}

Many wind farms are erected in areas where the site has complex topography. This enables to avoid misleading fertile agricultural lands and to keep windmills away from transport infrastructures. Moreover, there is the advantage of beneficiating from elevated wind speed which permits maximizing wind energy production [1]. However, in comparison with flat ground, airflow characteristics in hilly terrain are more uneven and wind potential is more delicate to estimate [2].

The flow of air occurring in the ABL overlaying a complex topography has been the subject of active research in many areas. Among the subjects that were investigated one finds
* Corresponding author.

E-mail: narjisse.amahjour@gmail.com 
identifying atmospheric pollution areas, forecasting smoke dispersion in fire events, evaluating wind energy and improving the installation of wind energy structures[3].

In addition to the acceleration experienced by air which increases wind speed in the upstream zone around the summit of hills, the adverse effects resulting from the turbulence caused by terrain and flow separation that takes place in the downstream zone are important features that should be considered in assessing effective wind energy [4].

It was recognized that wind flow pattern in the $\mathrm{ABL}$ is widely affected by the presence of upstream obstacles. It depends, among other things, on the mean roughness of the site and curvature of the obstacle [5]. To evaluate the amount of wind energy that is liable to be extracted by a wind turbine, for a given implementation site, the distribution of wind speed over the height of the wind turbine rotor has to be evaluated with adequate accuracy. As in this case the boundary layer turbulence characteristics in terms of skin-friction and shear stress are more complex, advanced Computational Fluid Dynamics (CFD) is required [6].

Carrying out CFD simulation of the ABL has been the subject of many studies: complex terrain [7, 8], pollutant dispersion $[9,10]$, wind load on turbines buildings [11] and urban environment [12]. In particular many studies have been examined by several research groups for studying the turbulent airflow around hill (i.e., [13, 14, 23, 24, 15-22]). Most of these works have emphasized the severe limitation resulting from the size of the problem yielded by the necessity to discretize the unbounded ABL domain, which increases considerably the demand on computing capacity.

Various turbulence models are used for predicting airflow in the ABL. Most of them are derived based on the Reynolds Averaged Navier-Stokes equations (RANS). This approach assumes the decomposition of an instantaneous quantity into its time-averaged and fluctuating parts. The problem is then governed by a simplified system of mean flow equations, which enables to avoid the difficulties resulting from the Direct Numerical Simulation (DNS) of explicit full time-dependent flow field. The main motivation of this approach is related to the fact that, in most CFD applications, knowing how turbulence affects the mean flow is enough and no real need exists to resolve all the details of the turbulent fluctuations.

Other flow prediction methods include Large Eddy Simulation (LES). This approach is based on time dependent calculations performed on space-filtered equations. Larger eddies are then explicitly calculated. The effect of small eddies on the flow pattern is considered through a refined "subgrid model". LES approach leads to enhanced representation of turbulence and constitutes an intermediate alternative between RANS based equations and the DNS. However computational cost associated to LES is still very high [25-27].

The RANS based approach leads to the apparition of a nonlinear Reynolds stress term, which requires extra steps in the modeling in order to close the mean flow equations. The closure of the problem was first performed by Boussinesq, who introduced the concept of eddy viscosity. The additional turbulence stresses are then treated by increasing the molecular viscosity with an eddy viscosity. Among the classical closure models following the RANS approach that have been extensively used one finds: standard $k-\varepsilon$ and SSTk - $\omega$ [28-33].

Considering hilly terrain, the above mentioned closure models have been used to predict wind flow in the ABL around hills. Due to its robustness, low computational cost, and reasonably accurate predictions, the standard $k-\varepsilon$ model was used. Castro et al. [17] have demonstrated that the mean flow in the upstream and on the top of the Askervin hill as predicted by the $k-\varepsilon$ model agrees well with experimental data. However, this model failed to accommodate for the effects of the streamline curvature and over-prediction of the turbulent kinetic energy was observed. Abdi et al. [34] have shown that the $k-\varepsilon$ model gives consistent results over most of the Askervin hill, except in the wake area on the leeward side of the hill, where excessive recirculation and reattachment length were observed. Loureieo et al. [35] presented a detailed comparison between numerical calculations and research laboratory data for air flow on a $2 \mathrm{D}$ hill by using the following turbulence models: $k-\varepsilon$, RNG $k-\varepsilon, k-\omega$, SST $k-\omega$, SSG-RSM- $\varepsilon$ and BSLRSM- $\omega$. They concluded that the SSTK $-\omega$ model yields more efficient results than the basic $k-\varepsilon$ model in terms of velocity and shear stress in the separation region. Yan et al. [36] studied flow structure around a hill by comparing SSTk $-\omega$ and $k-\varepsilon$. They pointed out that these models provide close results in terms of velocity curve except at leeward side of the hill where some discrepancies were noticed.

Recently, Uchida [37] presented the analysis of complex turbulent flow for the case of a 3D hill with high slopes. By conducting a comparison between LES and RANS models, he has shown that the LES, unsteady SSTK $-\omega$ give quite similar results to each other at the upstream, top and downstream of the steep hill. However, the results of the two RANS based models diverge from those provided by LES at the center of the vortex region.

Certainly, the capture of the recirculation zone on downstream of the hill following the large separated flow and turbulence production are difficult to simulate numerically within the context of RANS closure models. Some researchers have introduced the idea of adjusting the closure constants of turbulence models in terms of the characteristics of the boundary layer region in neutral atmospheric conditions: Panofsky et al. [38] for $k-\varepsilon$ model. Since then, the adjustment of closure constants has been employed in many studies [39-41]. Recently, a new set of closure constants for the SSTK - $\omega$ model that performed well in the empty computational domain was proposed [42, 43]. This set of closure constants will be applied here in an unprecedented manner to perform two-dimensional simulation via the SSTk $-\omega$ model in order to capture the circular motion of airflow in the ABL as induced by the presence of a hill obstacle. The obtained results have indicated a better description of the separated flow in the presence of strong curvatures. Although the model SSTk $-\omega$ is widely used in 
aeronautical applications, it receives limited attention research of airflow in hilly terrain simulation.

Many software packages are now available to users for CFD fluid flows analysis. They mostly have the benefit of being well accurate and quite handy by providing a genuine user interface [44]. However, monitoring adequately simulations for an original problem is still being far out of reach in many circumstances where the results are sensitive to actual mesh and other convergence criteria, in addition to the model capability. In this study, COMSOL Multiphysics, which is based on the specific Finite Element Method (FEM) [45], is used. Fundamentals settings associated with the FEM are first to be fixed by examining the model convergence in terms of the grid independence test, near wall treatment and the location of the border of the discretized finite domain of calculation.

This paper proposes at first a comparison of the following models standard $k-\varepsilon$ and SSTk $-\omega$ in order to evaluate their performances in the appropriate neutral ABL conditions corresponding to the Russian Hill (RUSHIL) wind tunnel experiment [46]. This involves monitoring CFD simulations with regards to the mesh resolution requirement and the pertinent set of closure parameters. It also considers the computational cost of the two models.

The second objective in this article is to carry out a detailed CFD study by comparing it to experimental data of the turbulent airflow over two shapes of hills in terms of velocity profiles during a long of the air domain and to investigate the effect of hills profile and turbulence models on wind speed-up. Therefore, it is significant to notice the impact of a different hill shaped on general flow behavior over complex terrain, which can contribute to finding the optimal turbine placements and to ensuring its reliability and appropriate performance.

This paper presents some new findings that aim at improving simulations of the $\mathrm{ABL}$ in complex terrain with hill shape obstacles. A methodology providing wise selection of near wall region treatment as function of the purpose of CFD simulation will be indicated. New closure parameters in the case of SSTk - $\omega$ taken from recent literature will be tested in capturing recirculation zones developing at the downstream of hills. In addition, the study was carried out to assess the efficiency of CFD model for describing the effect of topography in open complex terrain, which was considered by implementation of two different hill slopes.

The remainder of the paper is organized as follows: The formulation of the governing equations, constants are given in model formulation and model description are presented briefly in Section 2. The numerical procedure, computational domain, geometric description of the hill, and the appropriate flow parameters are presented in Section 3. The mesh description, the near-wall study of two turbulence closure models and the convergence test are described in Section 4 . The results obtained from the numerical simulations and the effect of the topography in the terrain are illustrated in Section 5, the conclusions and discuss the limitations are reported as a final point.

\section{GOVERNING EQUATIONS AND MODEL DESCRIPTION}

In RANS (Reynolds averaged Navier-Stokes) simulations in the case of steady incompressible flows, the Navier-Stokes equations in two spatial dimensions yield to solve the nonlinear Reynolds stress term and to close the system of equations [47]. The turbulence models provided in this section use the turbulence viscosity hypothesis concept that was developed by [48]. They correspond to the stress-rateof-strain relation for Newtonian fluid [49].

\subsection{Standard $k-\varepsilon$ model formulation}

Jones and Launder (1972) were the first to introduce the standard $k-\varepsilon$ turbulence closure model [50], modified by [51], it was implemented in COMSOL software as the default turbulence model. The two-transport equation of the $k-\varepsilon$ model was first used in applied CFD and is still the model largely used in many fields [52]. It solves for two turbulence parameters: $k$, the turbulence kinetic energy; and $\varepsilon$, the turbulence dissipation energy, respectively [6]. The standard closure coefficients implemented in transport equation for $k$ and $\varepsilon$ are given in Table 1 . In the present work, the coefficients of the $k-\varepsilon$ model have been modified according to the characteristics of the surface boundary layer in neutral atmospheric conditions recommended by [53], and it was implemented in Table 1 . In particular, previous research has shown that the closure model of turbulence has always been most common for industrial applications due to its high convergence rate and low storage requirements, but it is only valid for fully developed turbulence. It generally performs poorly in the area close to the wall and it is not valid to give accurate results for complex flows, also for strong curvature to the flow, specially, in the existence of strong adverse pressure gradients [54].

\subsection{Shear stress transport $k-\omega$ model formulation}

Menter [55], described the "shear-stress transport" SSTK - $\omega$ model. The SST model has been industrialized in two phases. The primary is the Wilcox $k-\omega$ model, which is meant to improve the robustness and forecasts in adverse pressuregradient boundary layers; the other one is the $k-\varepsilon$ model, which solves the problem of the sensitivity of the free-stream in the external region of the boundary layer. A blending function is implemented to combine the two models according to the distance from the wall. A blending function takes a value of one in the inner layer Wilcox $k-\omega$ and zero in the outer layer $k-\varepsilon$. The standards values of the closure coefficients SSTK - $\omega$ turbulence model are given in Table 2.

Table 1. Summary of the model closure coefficients used for the standard $k-\varepsilon$ turbulence model

\begin{tabular}{lllcccc}
\hline & $C_{\mu}$ & $C_{\varepsilon 1}$ & $C_{\varepsilon 2}$ & $\sigma_{k}$ & $\sigma_{\varepsilon}$ & $\kappa$ \\
\hline Standard & 0.09 & 1.44 & 1.92 & 1.0 & 1.3 & 0.41 \\
Neutral ABL & 0.033 & 1.176 & 1.92 & 1.0 & 1.3 & 0.42 \\
\hline
\end{tabular}


Table 2. Summary of the model closure coefficients used for the SST $k-w$ turbulence model

\begin{tabular}{lcccccccccc}
\hline & $\alpha_{1}$ & $\beta_{1}$ & $\sigma_{k 1}$ & $\sigma_{\omega 1}$ & $\alpha_{2}$ & $\beta_{2}$ & $\sigma_{k 2}$ & $\sigma_{\omega 2}$ & $C_{\mu}=\beta^{*}$ & $a_{1}$ \\
\hline Standard & 0.556 & 0.075 & 1.176 & 2 & 0.44 & 0.0828 & 1 & 1.168 & 0.09 & 0.31 \\
Neutral ABL & 0.413 & 0.0333 & 1.176 & 2 & 0.20 & 0.0368 & 1 & 1.168 & 0.028 & 0.31 \\
\hline
\end{tabular}

Then to adjust the features of the high turbulence flow, the coefficient value of $C_{\mu}$ was replaced by 0.028 based on the study [56] and the constant $a_{1}$ takes the value of 0.31 . Dealing with atmospheric flows, the coefficients of the model should be suitably modified according to the neutral atmospheric condition in Table 2 recommended by $[42,43]$.

The Governing equations of the standard $k-\varepsilon$ and SSTk $-\omega$ turbulence models mentioned previously can be presented in a universal form as follows:

$$
\rho \frac{\partial \bar{\varphi}}{\partial t}+\rho \overline{u_{j}} \frac{\partial \bar{\varphi}}{\partial x_{j}}-\frac{\partial}{\partial x_{j}}\left[\Gamma_{\varphi, e f f} \frac{\partial \bar{\varphi}}{\partial x_{j}}\right]=S_{\varphi}
$$

where $\varphi$ represents variables, $\Gamma_{\varphi, e f f}$ represents the effective diffusion coefficient, and $S_{\varphi}$ represents the source term of an equation. The mathematical formulations of the two turbulence models are implemented in Table 3; however, the constants and closure coefficients are in Table 1 and 2.

\section{NUMERICAL SETUP}

\subsection{Solver details}

The FEM has been used to discretize in space the governing equations presented previously. It is obvious that Galerkin formulation can lack stability for the Navier-Stokes equations. For the stationary solver, COMSOL uses Newton's method (Newton-Raphson) to solve the non-linear NavierStokes equations [45]. For the simulations of this work, a Direct Linear Solver was used due to them being more robust than iterative solvers. This was also the default choice made by COMSOL for most simulations. The direct solver makes use of Gaussian elimination, or LU factorization, to solve the linearized matrix system. For the simulations with the turbulence model, the variables of turbulence were solved separately from the velocity and pressure by using a segregated solver, and the default solvers chosen by COMSOL were always used. The "PARDISO/Parallel Direct Sparse Solver Interface" solver [57] was chosen for all our simulations, for solving large linear systems of equations on shared memory multiprocessors.

\subsection{Computational air domain}

The FEM simulation of our geometry was implemented by using COMSOL Multiphysics and was performed with Intel Core i5-3230M CPU@ $2.60 \mathrm{GHz}$ processors with 8,00 Go RAM on a 64 bits system. The computational air domain shown in Fig. 1 is similar to that used by [58] in their numerical analysis that reproduces the RUSHIL wind tunnel experimental setup (ERCOFTAC 69) carried out by [46]. The hill height $\mathrm{H}$ was set to $0.117 \mathrm{~m}$ but the value of the hill half-length $a$ was fixed by $3 \mathrm{H}$. The shape of the hill is given by the following parametric expression mentioned in [58]:

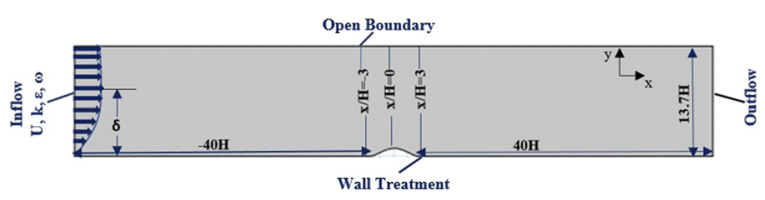

Fig. 1. Side-View of the computational geometry of present study

Table 3. Variables and Sources terms for the turbulence models

\begin{tabular}{|c|c|c|c|c|}
\hline & $\varphi$ & $\Gamma_{\varphi, e f f}$ & $S_{\varphi}$ & Constants \\
\hline $\begin{array}{l}\text { Reynolds filtered } \\
\text { variables for (a)-(b) }\end{array}$ & $u_{i}$ & $\mu+\mu_{t}$ & $\frac{-\partial P}{\partial x_{i}}$ & $\begin{array}{r}S_{i j}=\frac{1}{2}\left(\frac{\partial \overline{u_{i}}}{\partial x_{j}}+\frac{\overline{\partial u_{j}}}{\partial x_{i}}\right) \\
\Omega_{i j}=\frac{1}{2}\left(\frac{\partial \overline{u_{i}}}{\partial x_{j}}+\frac{\partial \overline{u_{j}}}{\partial x_{i}}\right)\end{array}$ \\
\hline (a)Standard $k-\varepsilon$ & $\begin{array}{l}k \\
\varepsilon\end{array}$ & $\begin{array}{l}\mu+\mu_{t} / \sigma_{k} \\
\mu+\mu_{t} / \sigma_{\varepsilon}\end{array}$ & $\begin{array}{c}P_{k}-\rho \varepsilon \\
C_{\varepsilon 1} P_{k} \varepsilon / k-C_{\varepsilon 2} \rho \varepsilon^{2} / k\end{array}$ & $\mu_{t}=C_{\mu} \rho \frac{k^{2}}{\varepsilon} ; P_{k}=\mu_{t} S^{2}$ \\
\hline (b)SSTk - $\omega$ & $\begin{array}{l}k \\
\omega\end{array}$ & $\begin{array}{l}\mu+\sigma_{k} \mu_{t} \\
\mu+\sigma_{\omega} \mu_{t}\end{array}$ & $\begin{array}{c}P_{k}-Y_{k} \\
P_{\omega}-Y_{\omega}+D_{\omega}\end{array}$ & $\begin{array}{c}S \equiv \sqrt{2 S_{i j} S_{i j}} \\
\mu_{t}=\frac{\rho a_{1} k}{\max \left(a_{1} \omega_{1}, S F_{2}\right)} ; Y_{k}=\rho \beta_{0}^{*} k \omega\end{array}$ \\
\hline & & & & $Y_{\omega}=\rho \beta \omega^{2} ; D_{\omega}=2\left(1-F_{1}\right) \frac{\rho \sigma_{\omega 2}}{\omega} \frac{\partial k}{\partial x_{j}} \frac{\partial \omega}{\partial x_{j}}$ \\
\hline & & & & $P_{\omega}=\frac{\rho \alpha P_{k}}{\mu_{t}} ; P=\min \left(P_{k}, 10 \rho \beta_{0}^{*} k \omega\right)$ \\
\hline
\end{tabular}




$$
\begin{gathered}
x=\frac{1}{2} \xi\left[1+\frac{a^{2}}{\xi^{2}+m^{2}\left(a^{2}-\xi^{2}\right)}\right] \\
|\xi| \leq a \\
y=\frac{1}{2} m \sqrt{a^{2}-\xi^{2}}\left[1-\frac{a^{2}}{\xi^{2}+m^{2}\left(a^{2}-\xi^{2}\right)}\right]
\end{gathered}
$$

where $m=n+\sqrt{n^{2}+1}$ and $n=H / a$ is the average slope.

In the piece of work, the hill is appointed as Hill3 according to which $\mathrm{a} / \mathrm{H}$ ratio and its corresponding maximum hill slope is $26^{\circ}$. The extended distance of the computational domain is \pm 40 up and downstream of the top of the hill to vertical height is $13.7 \mathrm{H}$ as shown in Fig. 1. The boundary layer depth is taken as $D=1 \mathrm{~m}$ with a roughness length fixed by $z_{0}=0.157 \mathrm{~mm}$, whereas a normalized friction velocity equals $u_{*} / U_{0}=0.047$. On another note, the Reynolds number based on boundary layer depth equals $R_{e \delta}=31200$ with the uniform velocity value being nominally $U_{0}=4 \mathrm{~m} / \mathrm{s}$.

\subsection{Boundary conditions}

The set of the fluid dynamics and turbulence governing equations mentioned in section 2 gives a full model for the description of turbulent flows. Therefore, it can be difficult to solve these equations due to the existence of the non-linear convective term presented in equation (1), which makes an extensive variety of length and time scales. Additionally, the hypotheses employed to derive the high Reynolds number model are not valid near walls in which the tangential wind speed disappears. A Suitable description of the boundary conditions is required. The different boundary conditions were fixed as velocity inlet and pressure outlet for the two side surfaces of the computational field, while the other surfaces (wall, hill, and top) have been identified as no-slip conditions.

In the context of ABL numerical simulations, completely developed inlet profiles for velocity and turbulent variables are usually imposed on the inlet of the computational air domain. The average velocity profile, turbulent kinetic energy, and dissipation rate under neutral ABL conditions proposed by [59] are used in this work and it has been mentioned in Table 4.

The wall function and enhanced wall treatment have been applied to specify the ground boundary conditions for the standard $k-\varepsilon$ turbulence model and the SSTK $-\omega$ turbulence model, respectively. The open boundary condition was defined on the top wall where a zero for the normal component of a vector and zero gradient for tangential have been applied to decrease computational cost, such as they are adequately far away from the hill to influence the flow features. In the right side of domain, the airflow is measured fully developed, however, the pressure fixed at the atmospheric pressure $P=P_{a t m}$ is applied in the outlet boundary condition, and zero flux for all other variables.

\section{MESH DESCRIPTION}

\subsection{Mesh generation and analysis}

The mesh for the two-dimensional model has been created using the definition of the triangle elements size for the completely computational domain and by determining the mesh distribution (quadratic element) close to the wall (Fig. 4) by fixing the number of layers in the boundary layer properties.

The mesh characteristics for the two turbulence models studied in this work, based on the thickness of the first layer $h$ for many types of meshes are presented in Table 5. The successive ratio employed for all the meshes is 1.2. This makes it possible to analyze the behavior of the different turbulence models and treatments approximately the walls according to the different precision regions of resolution as determined by the wall lift-off $\delta_{w}^{+}$and $l_{w}^{+}$.

The time of the numerical simulation is toughly influenced by mesh characteristics to calculate the most significant variables. However, the mesh must be refined to produce reliable results that are independent of the grid size, but at the same time, an unnecessary fine grid will greatly increase the

Table 4. Summary of boundary conditions

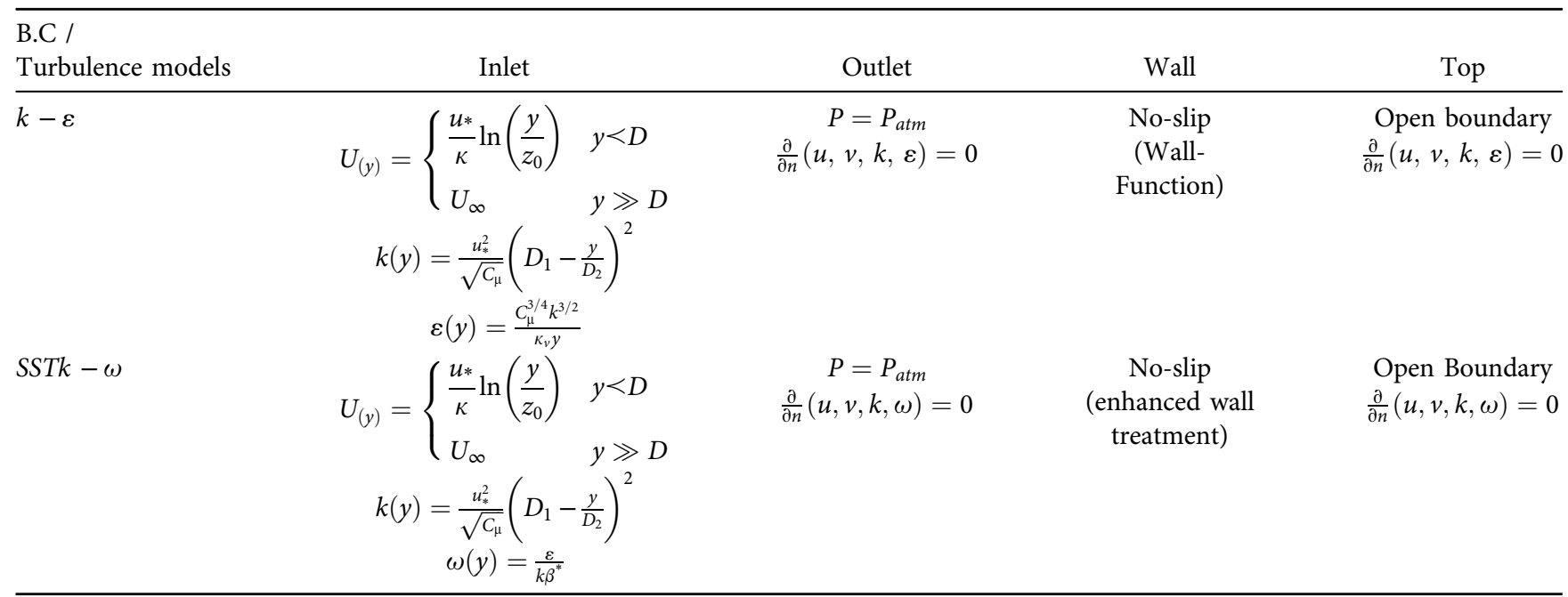


simulation time, which is one of the most important tasks for engineering problems to make time limitations and to achieve the fast and reliable solution. However, reducing the computational costs is an essential task. The parameters indicating computational performance are presented in $\mathrm{Ta}$ ble 5 below as solution time until convergence.

The application of the wall law at the first mesh cell of the computational grid yields to use a specific strategy of the dimensionless wall-lift off distance $\delta_{w}^{+}$in the boundary that is considered by the viscous sub-layer length scale. In this regard, the law of the wall usually characterizes the flow region close to the hill surface. Hence, to resolve the physical turbulence parameters approximate to the obstacle, also, to investigate the viscous effect that is enclosed to a thin wall adjacent region, the numerical computation should be started at some distance $\delta_{w}$ from the wall [45]. The wall function hypothesis introduced by [60] shows the ability to check the dimensionless $\delta_{w}^{+}$value such that the $\delta_{w}$ distance will not fall within the viscous sublayer. Then, the wall function can avoid the incapability of the model to envisage a logarithmic velocity profile close to the wall. According to [61], the value of $\delta_{w}^{+}$equals to 11.06 , which means the point at which the logarithm intersects the viscous sublayer. For the $k-\varepsilon$ turbulence model, the mesh got coarser around hill to ensure $11.06 \leq \delta_{w}^{+} \leq 300$, but for more accuracy to capture the variables gradient we chose the finer mesh.

In COMSOL Multiphysics code, the wall law is gotten by the namely scalable wall function, whose $\delta_{w}^{+}=u_{\tau} \delta_{w} / \nu$ value employed in the log-expression is limited on the $\max \left(11.06, h^{+} / 2\right)$. At separation points, the vanishing of the wall-shear stress requires to devise a specific approach for avoiding a singularity of log-relation. An alternative method is to assume $u *=C_{\mu}^{1 / 4} k^{1 / 2}$ like the tangential velocity in the logarithmic term. Thus, $u *$ can be calculated from the logexpression. The results found using the wall function are significantly dependent on mesh characteristics; notably, a denser mesh does not give results with increasing precision [35].
The surface resolution should be approximately 11.06 on the walls surrounding the fluid. If the value is higher, it means that the mesh is relatively coarse and that the precision can be compromised.

Another technique to flow simulation is to control the dimensionless center named $l_{c c}^{+}$considering models that include a near wall region (viscous sublayer), which are called low-Reynolds number modes. Normally, this type of treatment is used for the SSTK - $\omega$ turbulence model. It is provided to make sure the mesh refinement is sufficient, which needs a mesh resolution $l_{c c}^{+} \approx 0.5$ [45]. Therefore, this model has the ability to determine the viscous flow effects when the mesh is sufficiently fine near the walls. For this purpose, their use needs a high consummation regarding computer-storage and execution time, and it should take into account the effect of small values of $l_{c c}^{+}$on the convergence rate.

Therefore, fixing the distance from the wall in the computational domain, the refinement is relatively natural. However, importantly, the distance used to calculate the wall law remains constant, which yields to decreasing a numerical error in FEM.

Four different mesh sizes are indicated in Table 5 and schematized in Fig. 2 below to investigate the concept of sensitivity of dimensionless distance from the wall in flow domain as a mean if identifying the suitable near wall treatment. For these types of simulation, it is recommended to check the wall lift-off in viscous unit $\delta_{w}^{+}$and $l_{c c}^{+}$before basing on the mesh.

\subsection{Convergence criteria and grid independence study}

When the successive results of the CFD simulation do not change significantly by adding further iterations, the solution converges. All the simulations presented in this part have converged on a solution whose relative error is less than $10^{-4}$. On the other hand, it should be noted that a

Table 5. Computational performance of the various turbulence models

\begin{tabular}{|c|c|c|c|c|c|c|c|}
\hline $\begin{array}{l}\text { Turbulence } \\
\text { models }\end{array}$ & $\begin{array}{c}\text { Type of the wall- } \\
\text { treatment }\end{array}$ & $\begin{array}{l}\text { Type of } \\
\text { Mesh }\end{array}$ & $\mathrm{h}$ & $\begin{array}{l}\text { Number of } \\
\text { elements }\end{array}$ & $\begin{array}{l}\text { Number of degrees of } \\
\text { freedom }\end{array}$ & $\begin{array}{l}\text { Solution } \\
\text { time }(\mathrm{s})\end{array}$ & $\begin{array}{c}\text { Distance from } \\
\text { the wall }\end{array}$ \\
\hline \multirow[t]{4}{*}{$k-\varepsilon$} & High Reynolds & $\begin{array}{l}\text { M1 } \\
\text { Coarse }\end{array}$ & $0.0577 \mathrm{H}$ & 4,485 & 49,819 & 362 & $11,6 \leq \delta^{+} \leq 39$ \\
\hline & & $\begin{array}{c}\text { M2 } \\
\text { Normal }\end{array}$ & $0.0425 \mathrm{H}$ & 7,364 & 78,265 & 506 & $11,6 \leq \delta^{+} \leq 39$ \\
\hline & & M3 Fine & $0.0303 \mathrm{H}$ & 12,238 & 122,989 & 770 & $11,6 \leq \delta^{+} \leq 29$ \\
\hline & & $\begin{array}{l}\text { M4Extra } \\
\text { Fine }\end{array}$ & $0.0212 \mathrm{H}$ & 18,487 & 179,906 & 1,292 & $11,6 \leq \delta^{+} \leq 21$ \\
\hline \multirow[t]{4}{*}{$S S T k-\omega$} & Low Reynolds & $\begin{array}{c}\text { M1 } \\
\text { Coarse }\end{array}$ & $\begin{array}{c}3.035 \mathrm{e}- \\
3 \mathrm{H}\end{array}$ & 4,485 & 49,317 & 1,021 & $0,4 \leq l_{c c}^{+} \leq 4$ \\
\hline & & $\begin{array}{c}\mathrm{M} 2 \\
\text { Normal }\end{array}$ & $\begin{array}{c}1.821 \mathrm{e}- \\
3 \mathrm{H}\end{array}$ & 7,364 & 77,591 & 1,463 & $0,4 \leq l_{c c}^{+} \leq 2,7$ \\
\hline & & M3 Fine & $\begin{array}{c}7.286 \mathrm{e}- \\
4 \mathrm{H}\end{array}$ & 12,238 & 122,179 & 2,171 & $0,2 \leq l_{c c}^{+} \leq 1,8$ \\
\hline & & $\begin{array}{l}\text { M4 Extra } \\
\text { Fine }\end{array}$ & $\begin{array}{c}6.071 \mathrm{e}- \\
4 \mathrm{H}\end{array}$ & 18,487 & 178,936 & 2,964 & $0,1 \leq l_{c c}^{+} \leq 1$ \\
\hline
\end{tabular}




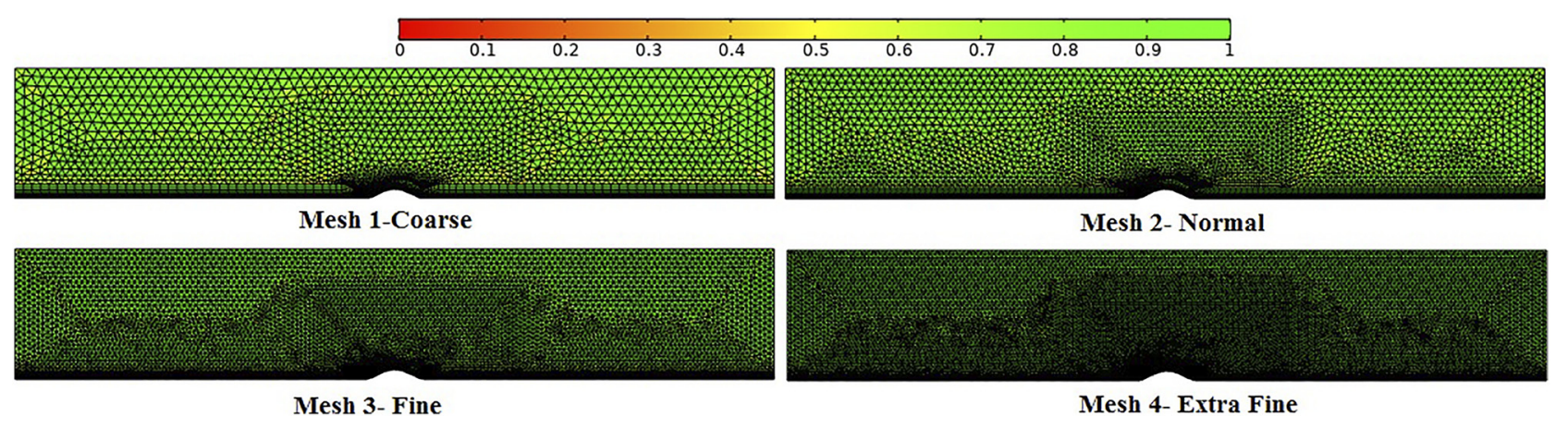

Fig. 2. Analyzed mesh sizes and Quality: Coarse mesh, Normal mesh, Fine mesh, Extra Fine mesh

variation in the damping factor for each variable of speed and turbulence has been achieved until reaching convergence.

A grid independence study was investigated to confirm that the results should be independent during the additional refinements. This piece of work was based on simulations executed the average velocity takes as the convergence criteria.

Figure 3 showed the comparison of the numerical computation of the mean velocity for standard $k-\varepsilon$ and SSTk $-\omega$ turbulence models in terms of different sized grids such $4,485,7,364,12,238$, and 18,487 to ensure grid independence of the calculations.

At the second level of the mesh (7,364 elements), it shows no further changes for the average velocity obtained by using the $k-\varepsilon$ model, although the results obtained with this turbulence model changed down to the fourth grid level
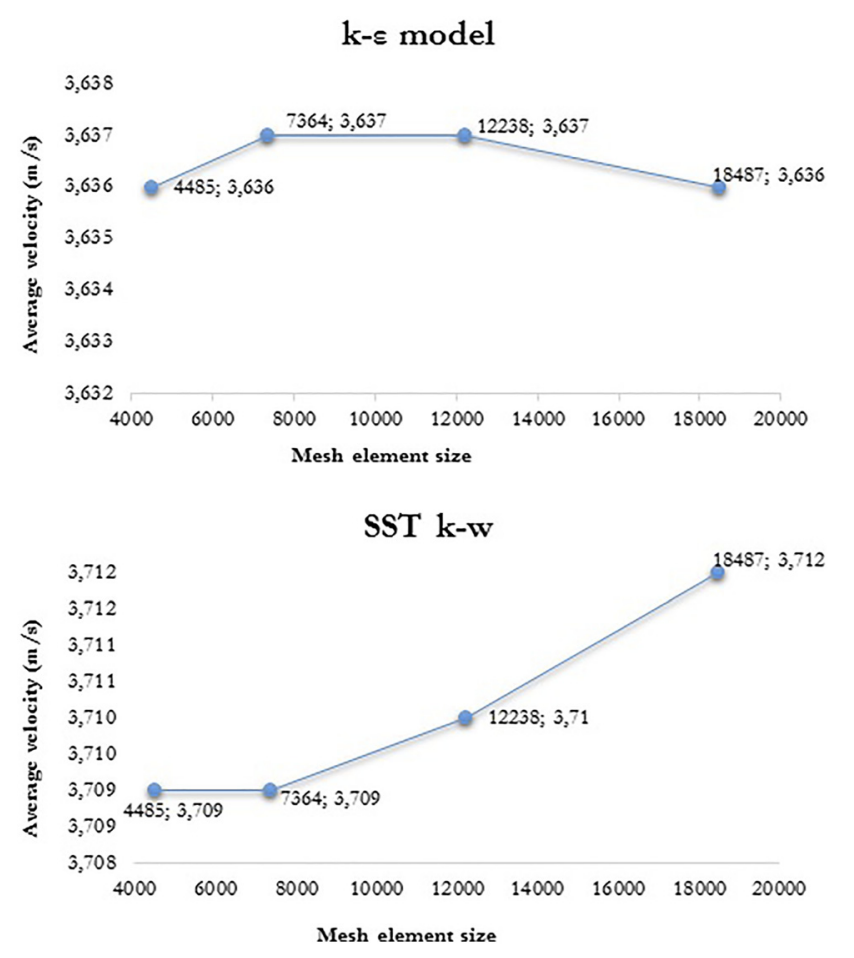

Fig. 3. Grid convergence of the average velocity from difference size element for two turbulence models: standard $k-\varepsilon$ and SST $k-w$
(18,487 elements). Though small differences remained after the application of the SSTk - $\omega$ model, the average velocity showed small variation following the second grid level $(7,364$ elements).

Finally, these numerical computation lead to the conclusion that it is more adequate to ensure results on the two turbulence models by choosing the mesh with 12,238 elements, independently of the mesh size.

\subsection{Mesh scheme}

A free triangular mesh was used inside the flow stream away from the walls although boundary layer was added close to the walls. Since the velocity distribution changes immediately normal to the wall, near to the boundary, and slightly in the tangential direction of the wall. To achieve sufficiently small wall lift-off, boundary layer meshes are needed. They can be generated automatically in COMSOL. The boundary layers mesh is smaller than the different places in whole domain, which was made to contain quadrilateral elements strongly packed in the direction normal to the wall and thinly in the tangential direction (see Fig. 4). Additionally, the all-sharp edges and contours of flow separation require the mesh refinements. It is therefore a suitable way to use denser meshes, which implied smaller elements just in the most sensitive areas, where unstructured meshes have been used in this work for the large spatial variation of the examined fields.

The Finer Mesh (M3) has been created using the parameters in Table 6. This is the mesh used for all simulations in this work.

\section{FLOW ANALYSIS OVER A STEEP SHAPED HILL 3}

\subsection{Effect of turbulence models on wind speed profiles: Validation with wind tunnel data}

The simulation results of the two turbulence models for airflow over a steep shaped hill (H3) were performed to their comparison with the wind tunnel data from [46]. The streamwise at vertical plane $\mathrm{y}=0 \mathrm{~m}$ by two turbulence models including standard $k-\varepsilon$ and SSTk $-\omega$ in neutral conditions of the boundary layer are shown in Fig. 5. 


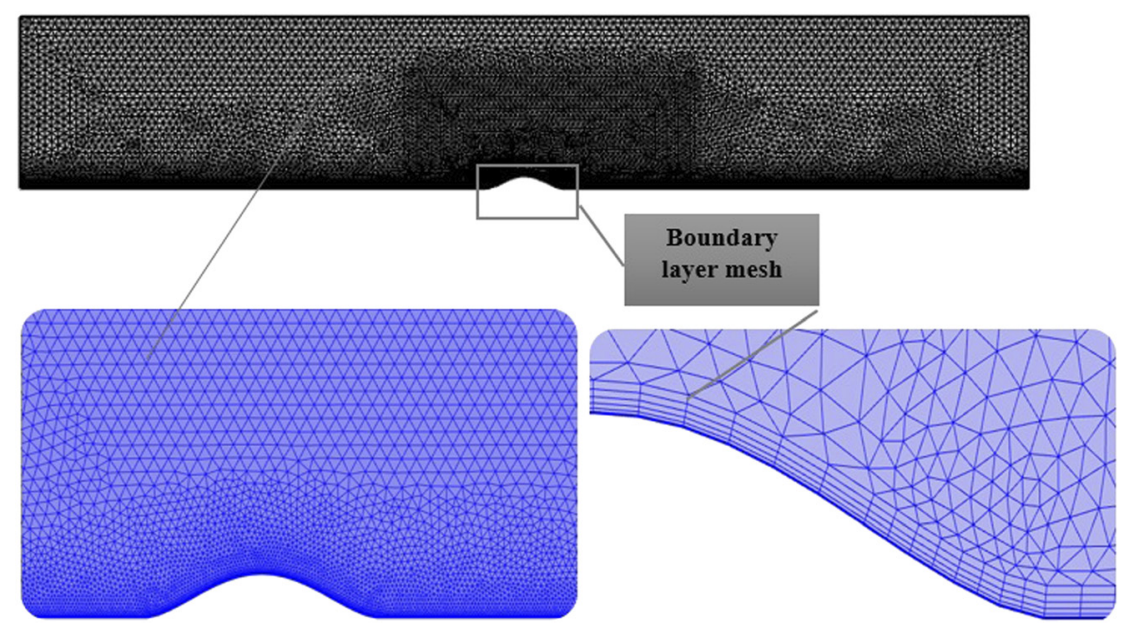

Fig. 4. The mesh structured (up), the detailed view of the mesh hill (down)

Table 6. Property of the mesh shown in Fig. 6

\begin{tabular}{lcc}
\hline Configuration & Domain & Values \\
\hline Mesh size & Air & Max element size (Block A):0.072m \\
& & Min element size (Block C): \\
& & $0.0032 \mathrm{~m}$ \\
Corner & Min. angle between the limits: \\
Refinement & 240deg \\
Boundary layers & & Element size scale factor: 0.35 \\
& & Number of layers: 10 \\
& & Growth rate: 1.2 \\
\hline
\end{tabular}

Therefore, this figure presents the comparison of expected results for the vertical profiles of the horizontal velocity component at $\mathrm{x} / \mathrm{H}=-3$ (upwind), $\mathrm{x} / \mathrm{H}=0$ (summit), $\mathrm{x} / \mathrm{H}=3$ (downwind) of the hill with the experiment RUSHIL data. As indicated from the profiles distributions, the correspondence between the measured data forecasted by the standard $k-\varepsilon$ and SSTk $-\omega$ models is properly good though there are slight discrepancies.

Additionally, it is noteworthy that the $\mathrm{x}$-velocity profiles for two turbulence models at $\mathrm{x} / \mathrm{H}=-3$ near the inlet boundary agree quite well to those measured in the wind tunnel testing as illustrated in Fig. 5 (a). However, the predicted velocity with these models tends to give different results at locations behind the steep slope of the hill. It was found that the acceleration over the crest of the $2 \mathrm{D}$ hill $\mathrm{x} /$ $\mathrm{H}=0$ obtained by CFD modelling Fig. 5 (b) in the case of the $k-\varepsilon$ turbulence model predicts a higher average acceleration from the surface to those of experience. In addition, it can be seen that this model after the accelerated region gives similar predictions for the rest of the height, and gives slightly higher speeds near the surface than those of the SSTK $-\omega$ turbulence model.

On the other hand, the horizontal velocity profile calculated by using the SSTK $-\omega$ model close to the downstream boundary $\mathrm{x} / \mathrm{H}=3$ by using neutral closure coefficients shows closer results by comparison by one predicted SSTK $-\omega$ by using standard coefficients and by the further model (see Fig. 5 (c)). These results prove that the effects of the hill have been increased on this location and produced an important recirculation region. Subsequently, the separated point is taken accurately corresponding to the higher value of reattachment length as observed in Fig. 6 (b). The forecast by the standard $k-\varepsilon$ model in neutral condition is significantly diverse from the experiment in this surface. Overall, the SSTK - $\omega$ model gave more agreement when comparing to the experimental data and performed the re-attachment length similar to LES. It is due on the closure coefficients of the neutral boundary layer condition that was used in the present work.

It should be noted that the standard $k-\varepsilon$ turbulence model under neutral conditions has been found to produce some separation in the wake of the hill (Fig. 6 (a)), but it underestimates the size and degree of recirculation zone, suggesting faster flow recovery. On the other hand, the SSTK $-\omega$ turbulence model in neutral condition gave the best prediction of the separated region directly in the wake of the hill, and it also showed the best correspondence with the experimental measurements for the reattachment point as shown in the Table 7.

Generally, the differences predicted among the standard $k-\varepsilon$ and SSTK $-\omega$ turbulence models indicate their different performances in simulating the shear layer flow and flow separation behind the hill. For more pronouncing the dissimilarity between the high and low closures turbulence models, a three-dimensional flow is fully suggested.

\subsection{CFD results and discussion}

The velocity and pressure contours plots resulting of the two-dimensional computational domain under neutral $\mathrm{ABL}$ condition are presented in Fig. 7 and Fig. 8. It is examined that the isovalue of the velocity contour for the models predicts a deceleration of the flow immediately upstream from the hill, followed by an acceleration of the windward slope with a maximum speed at the top, then a negative flow in the separation region. Downstream, along the slope, all these phenomena predict a vortex with a negative eddy 
(a)

WindWard $\mathrm{x}=-3 \mathrm{H}$

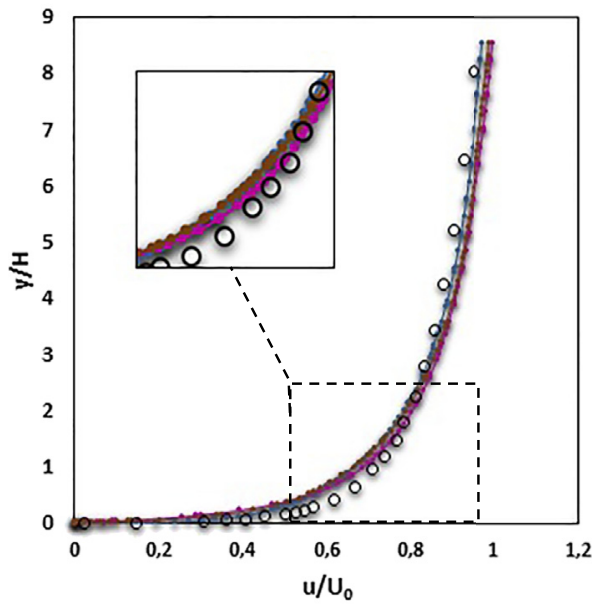

(b) Summit $\mathrm{x}=0 \mathrm{H}$

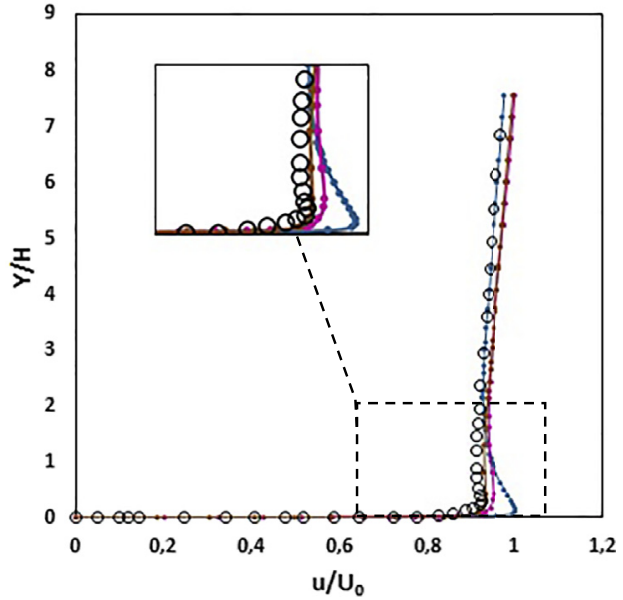

- standard $k-\varepsilon$ neutral ABL condition

- SSTk-w neutral ABL condition

— SSTk-w standard condition

- Rushil Experiment

- Rushil Experiment

(c) LeeWard $\mathrm{x}=3 \mathrm{H}$
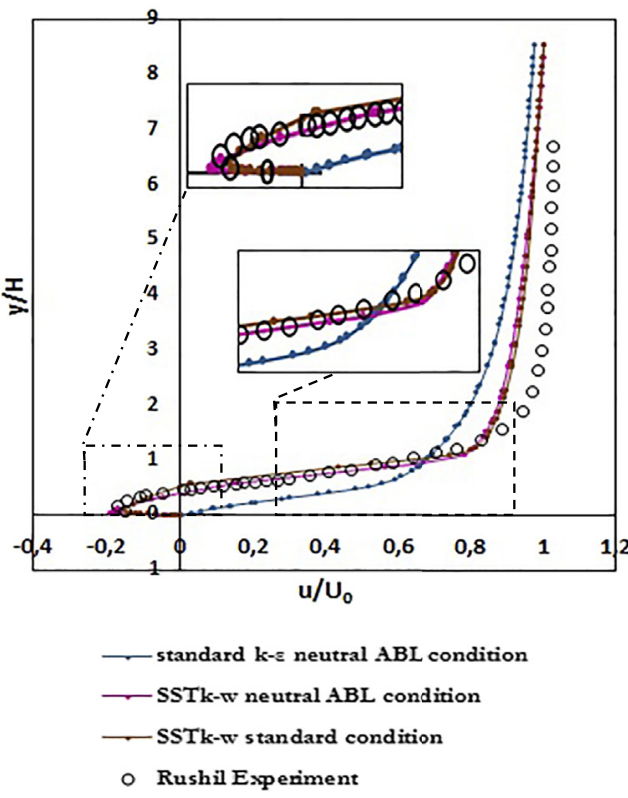

Fig. 5. Horizontal -Velocity profiles in comparison by wind tunnel experience: (a) upstream of the hill; (b) top of the hill; (c) downstream of the hill

direction. Another observation is the convergence in the fastest upper levels of the flow fields for the SSTK - $\omega$ turbulence model, which corresponds to a significant thickness of the boundary layer and more diffusive, so they tend to underestimate the velocity in the outer layer.

The pressure distribution obtained by two turbulence models used are shown in Fig. 8 to envisage the structure of the flow in the stream for the $2 \mathrm{D}$ case. It can be represented in the form of pressure level curves the entire computational domain with the two RANS models used the general flow characteristics and the overall forecast of upstream, summit and downstream are similar, although some differences can be observed. In the case of a boundary layer near to the hill, the relative pressure of $k-\varepsilon$ and SSTk $-\omega$ accelerates upstream of the surface of the hill and decelerates downstream in a recirculation zone.

However, two turbulence models create a low-pressure zone at the top of the hill when the flow returns to the surface; the relative pressure of SSTK - $\omega$ decelerates in the leeward side, which results in a large recirculation region. On the other hand, the presence of an adverse pressure gradient in the windward side of the obstacle leads to the separation of the flow from the hill surface. Furthermore, the pressure levels are over-predicted with the $k-\varepsilon$ model. 
(d)

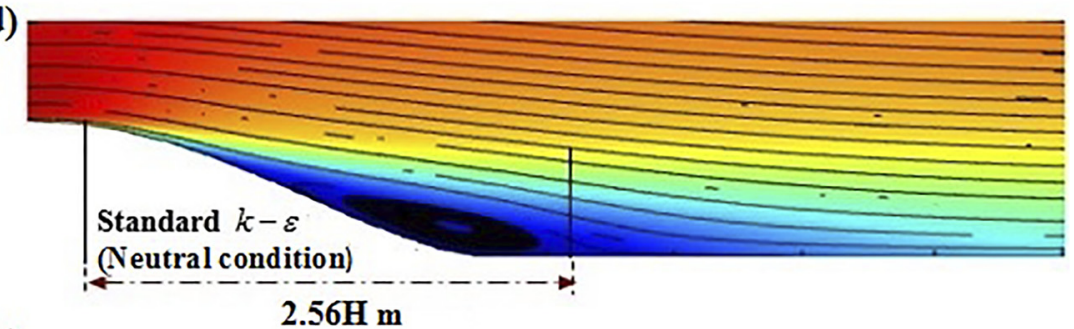

(e)

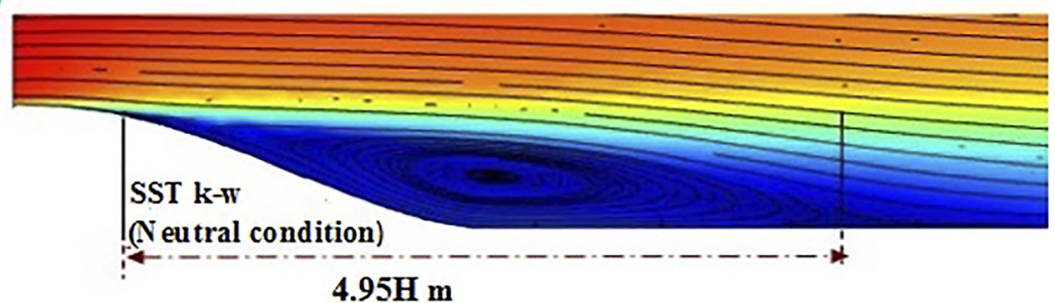

(f)

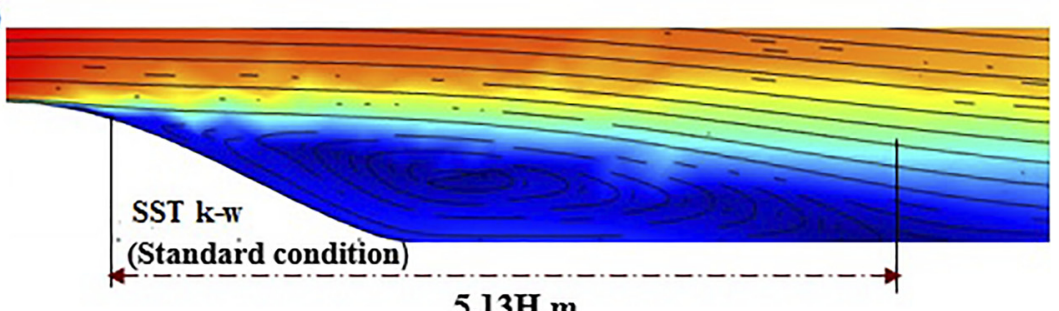

Fig. 6. Two-dimensional predictions of the separation and reattachment point behind a hill (H3)

Table 7. Measured and predicted separation, reattachment and recirculation lengths behind hill

\begin{tabular}{lcccc}
\hline Turbulence models & Source & Separation point & Reattachment Point & Recirculation length \\
\hline standard $k-\varepsilon$ (neutral ABL condition) & Present work & $0.85 \mathrm{H}$ & $3.41 \mathrm{H}$ & $2.56 \mathrm{H}$ \\
SSTk $-\omega$ (neutral ABL condition) & Present work & $0.51 \mathrm{H}$ & $5.46 \mathrm{H}$ & $4.95 \mathrm{H}$ \\
SSTk $-\omega$ (standard condition) & Present work & $1.28 \mathrm{H}$ & $6.41 \mathrm{H}$ & $5.13 \mathrm{H}$ \\
«Modified» standard $k-\varepsilon$ & Fluent [58] & ----- & $4.1 \mathrm{H}$ & ---- \\
LES & {$[26]$} & $---1-$ & $5.75 \mathrm{H}$ & --- \\
Wind tunnel experiment & {$[46]$} & $0.5 \mathrm{H}$ & $6.5 \mathrm{H}$ & $6 \mathrm{H}$ \\
\hline
\end{tabular}

Although the SSTK $-\omega$ model under-predicted pressure levels due to the earlier presence of a windward side flow separation and the existence of a great reverse flow region (see Fig. 8).

\section{INFLUENCE OF 2D HILL SLOPES SHAPE WITH DIFFERENT TURBULENCE MODELS}

The implementation of wind turbines in an optimal position with high wind speeds is considered a challenge and important during onshore wind siting to achieve extra performance of the power output and the effectiveness of wind farms.

The flow around complex terrain has been the subject of numerous field measurements and experimental wind-tunnel operations. The variations in the flow conditions due to changes in the wind directions is the most important point leading to the study of more idealized flow situations with simplified terrain geometries. The investigation of the flow over the bound escarpment in Denmark by Lange et al. (2006) and the study of the flow over a generalized isolated hill by using different inflow conditions presented by [62] can ensure and give more details for these views.

The flow development over hills is largely dependent on their steepness, where the flow separation disappears with lower steep hill, the comportment of the logarithmic boundary layer is similar to that observed on flat terrain [63]. On the other hand, steeper sloped construct the separation surfaces on the trailing edge of a hill [64] has shown that this phenomenon can be deflected in some cases towards the ground caused by the lee waves induced by hills.

The acceleration on the top of the hill leads to increased production of energy in wind farm but not always positively. However, it also induces negative effects due to the presence of several features like the increasing levels of turbulence and wind shear. For purposes to benefit the acceleration of wind speeds, to enable accurate predictions of the flow and at the 

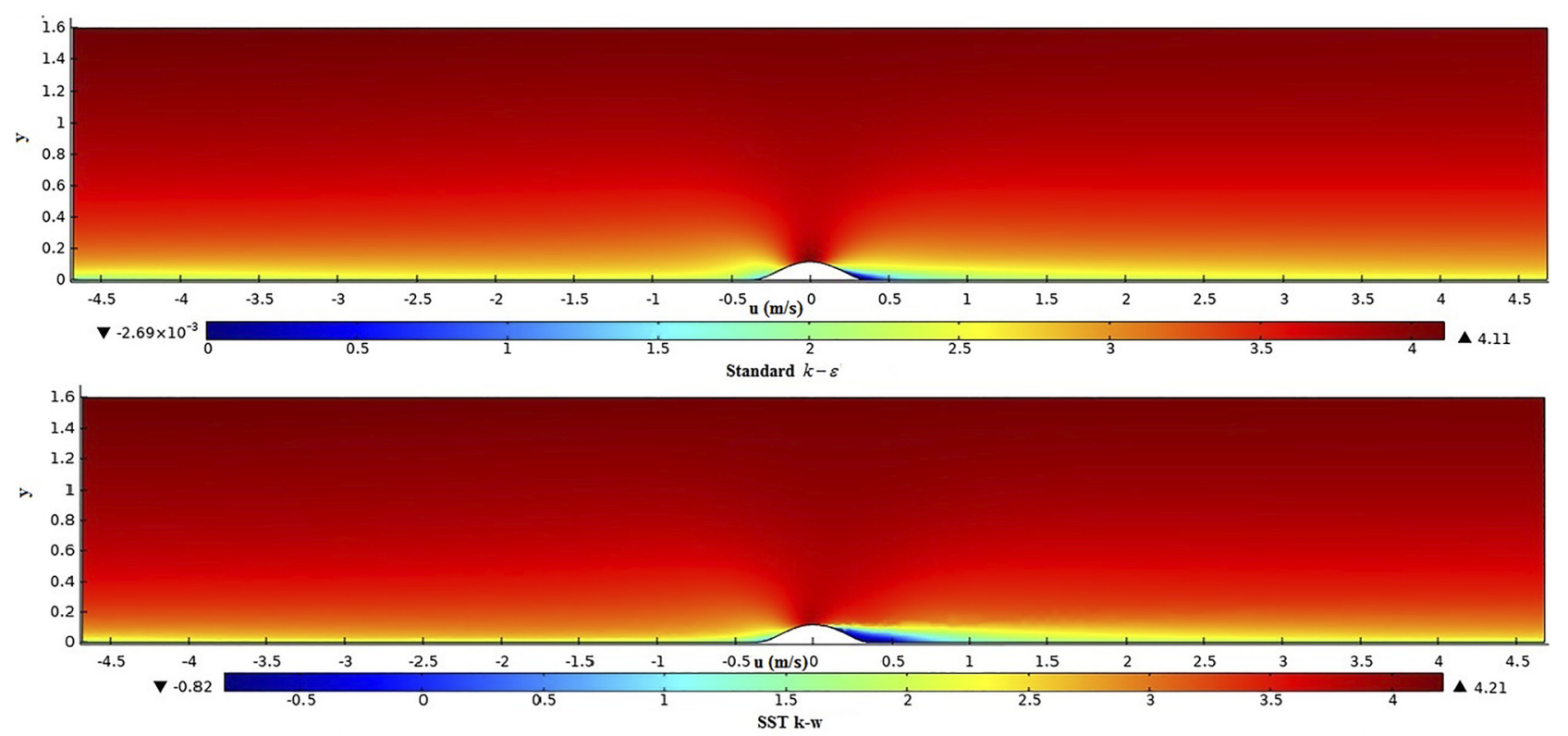

Fig. 7. Velocity contours of the CFD simulation results for standard $k-\varepsilon$ (line 1) and SSTk $-\omega$ (line 2) turbulence models (the unit of the $\mathrm{x}$-velocity: $\mathrm{m} / \mathrm{s}$ )
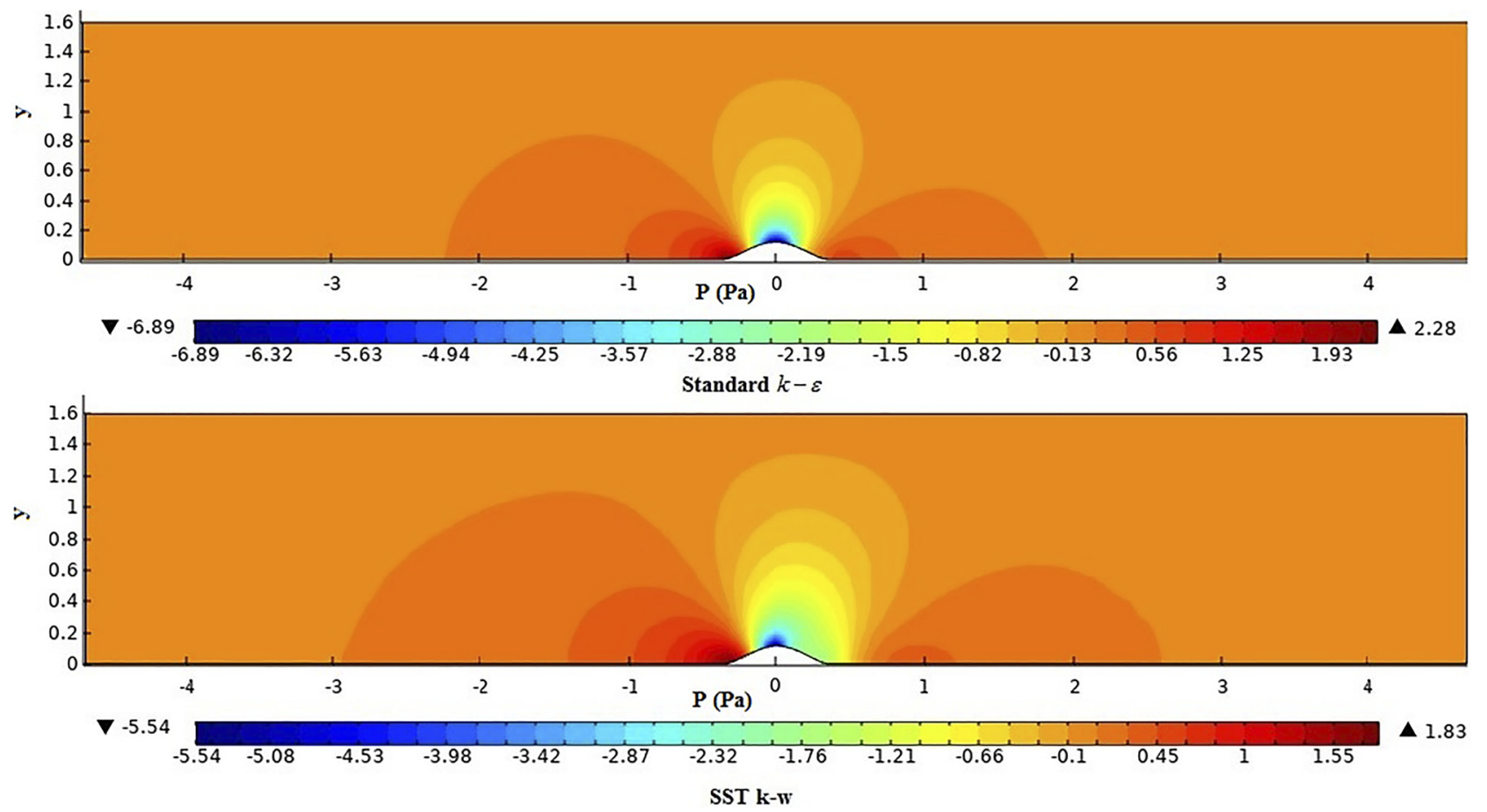

Fig. 8. Pressure contours of the CFD simulation results for standard $k-\varepsilon$ (line 1) and SSTk $-\omega$ (line 2) turbulence models (the unit of the relative pressure: $\mathrm{Pa}$ )

same time to eliminate the negative effects, the knowledge of the fundamental mechanisms governing flow over hilly terrain, topographical features of wind farms located in complex terrain are necessary [65]. Therefore, it is significant to notice the impact of different hill shapes on general flow behavior over complex terrain.
Figure 9 presents the shape of sloped hills used in this piece of the work, they are defined by the parametric equation specified in section 3.2. The slopes called here by $\mathrm{Hill} 3$ and Hill5 as function to their $\mathrm{a} / \mathrm{H}$ ratios and according to their maximum hill slopes are $26^{\circ}$ and $16^{\circ}$, respectively as shown in Table 8 and Fig. 9. 


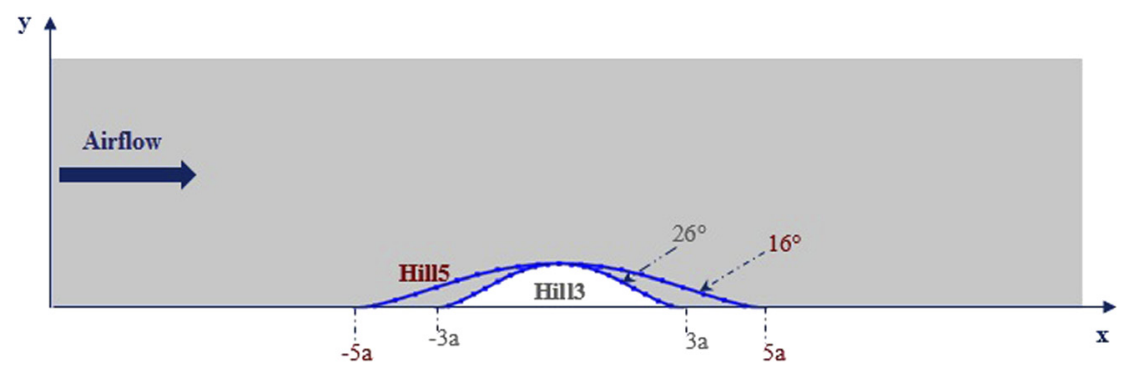

Fig. 9. Hills slopes configurations

Table 8. Representation of hill characteristics

\begin{tabular}{lccccc}
\hline Name & $H(m)$ & $L(m)$ & $H / L$ & Slope & $z_{0}(m)$ \\
\hline RUSHIL H3 & 0.117 & 0.702 & 0.166 & $26^{\circ}$ & $0.157^{*} 10^{-3}$ \\
RUSHIL H5 & 0.117 & 1.170 & 0.1 & $16^{\circ}$ & $0.157^{*} 10^{-3}$ \\
\hline
\end{tabular}

\subsection{Effect of turbulence models and hills shape on velocity profiles: Comparison of experiments data with CFD results}

The comparison of the CFD simulation and experience measurements results are presented in Fig. 10 below using $\mathrm{x}$-velocity as an essential parameter. The longitudinal velocity over the long measurement field for the two slopes $\mathrm{H} 3$ and $\mathrm{H} 5$ under two turbulence models $k-\varepsilon$ and SSTk $-\omega$ are normalised with uniform velocity $U_{\infty}$. The results evaluated in six points in total, such as $\mathrm{x}=-3 \mathrm{H}, \mathrm{x}=-1.5 \mathrm{H}$, $\mathrm{x}=0, \mathrm{x}=1.5 \mathrm{H}, \mathrm{x}=3 \mathrm{H}$ and $\mathrm{x}=9 \mathrm{H}$ for the steep slope $\mathrm{H} 3$ and $x=-5 H, x=-2.5 H, x=0, x=2.5 H, x=5 H$ and $\mathrm{x}=15 \mathrm{H}$ for the slight slope, are shown in Fig. 10.

The results calculated by these two models are in agreement in most situations, except for differences on the downstream side of the hill. These curves include their comparison with the experimental measurements in the six positions. As we can see, at the measurement positions
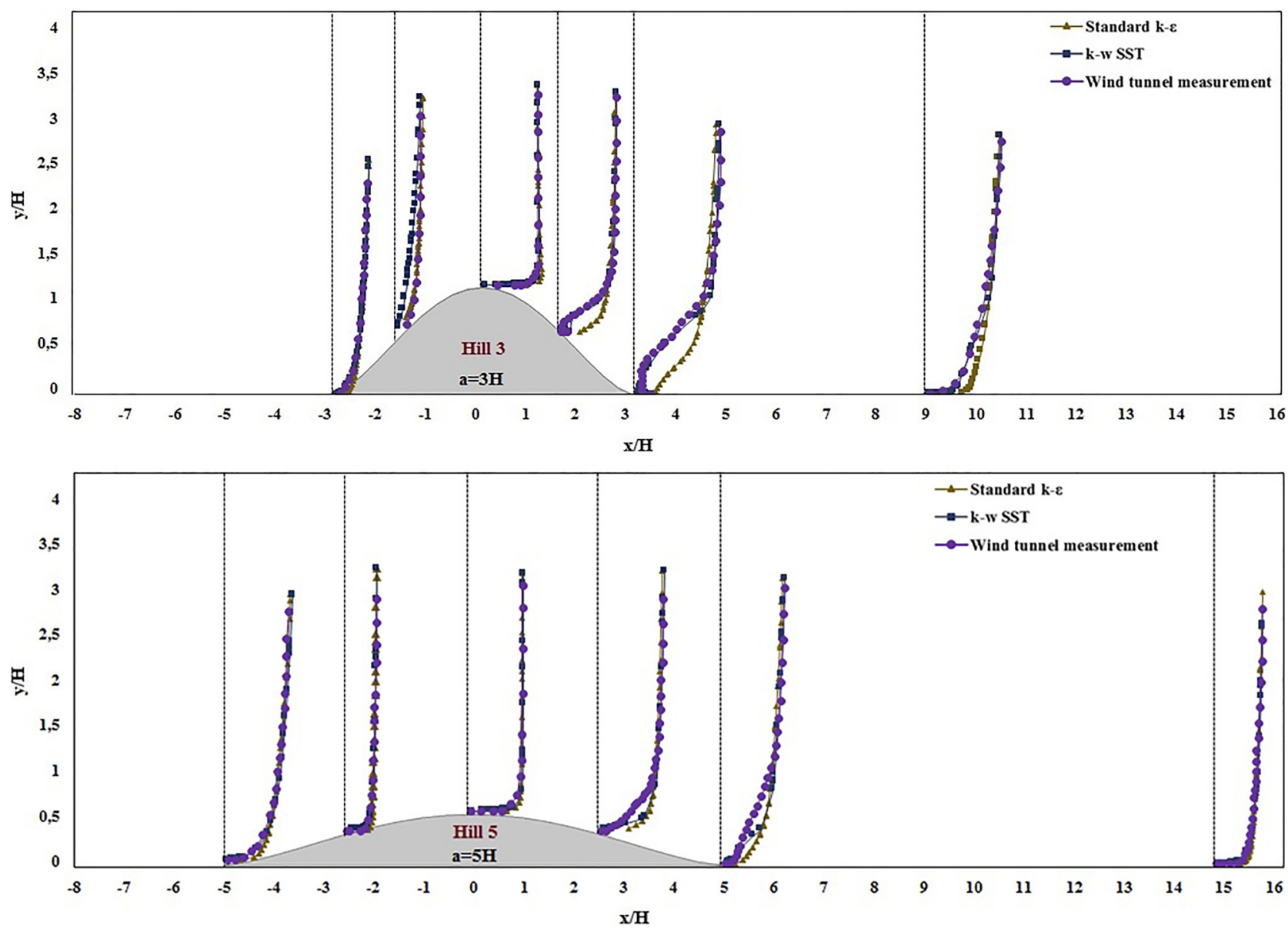

Fig. 10. Comparison of the normalized velocity profiles relative to the measurement on the 2D hills H3 (top) and H5 (bottom) 
$\mathrm{x} / \mathrm{H}=-3$ and -1.5 , upstream from the hill, the speed profiles are similar for the slope $\mathrm{H} 3$ (Fig. 10 (top)) except in the case at $\mathrm{x} / \mathrm{H}=-1.5$, a slight difference is marked for the SSTk $-\omega$ model and this may be due to the effect of the hill and its roughness is perceived near the wall up to the height $\mathrm{y} / \mathrm{H}=0.9$. Furthermore, in the velocity profiles at the points given by $\mathrm{x} / \mathrm{H}=-5,-2.5$ no significant difference is observed for the slope H5 (Fig. 10 (bottom)) with the $k-\varepsilon$ and SSTK $-\omega$ turbulence models.

\subsection{Simulation results and discussion: Effect of turbulence models and hills shape on speed-up factor profiles}

The variations of the wind speed around the surface of hills are plotted as a function of the ratio of the average wind speed (speed-up $\Delta S$ ). This parameter is equal to the ratio of the wind speed over the crest of the hill divided by the reference wind speed at the same local height above the wall some distance upstream where the flow is not affected by the slope.

$$
\Delta s=\frac{\bar{U}(x, z)-\bar{U}_{0}(z)}{\bar{U}_{0}(z)}=\frac{\Delta \bar{U}(x, z)}{\bar{U}_{0}(z)}
$$

The speed-up $\Delta S$ on the top of two hill slopes (H3 and H5) obtained by 2D CFD modeling is presented in Fig. 11 for the two turbulence models $k-\varepsilon$ and SSTk $-\omega$. The overspeed becomes more and more important as the speed of the flow increases. The negative values of $\Delta S$ are a good indicator of the birth of the shear layer upstream of the summit.

On the higher slope $\left(\phi=26^{\circ}\right)$, it observed a speed-up profile is fully developed for a height of $\mathrm{y}=1.71 \mathrm{H}$ and more precisely for the turbulence model $k-\varepsilon$ in Fig. 11 (a), it takes a significant speed-up value and a peak of the wind speed equal to $3.84 \mathrm{~m} / \mathrm{s}$, compared to that of reference. For a slight slope $\left(\phi=16^{\circ}\right)$, the value of $\Delta S$ for the same model of turbulence in Fig. 11 (b) is equal to $3.76 \mathrm{~m} / \mathrm{s}$. This shows that the shape of the slope has an important effect on the prediction of speed acceleration at the top of the hill.

For the case of the SSTk - $\omega$ turbulence model, and for the two high and low slopes $\left(\phi=26^{\circ}\right.$ et $16^{\circ}$ ) (Fig. 11 (c and d)), more similar speed-up profiles are provided for a height of $y=1.71 \mathrm{H}$, such as air velocity takes the value of $3.76 \mathrm{~m} / \mathrm{s}$ for the H3 slope and $3.7 \mathrm{~m} / \mathrm{s}$ for the $\mathrm{H} 5$ slope. However, the SSTk $-\omega$ model underestimated the acceleration compared to the $k-\varepsilon$ model.

For the case of the height $\mathrm{y}=5.13 \mathrm{H}$ and more precisely, moving away from the hill for the two slopes H3 and H5 for the SSTK - $\omega$ model, one can see that the behavior of the rate of the average wind speed started to be similar until arriving at the uniform region of the domain $y=1 \mathrm{H}$.

The comparison of velocity contours by considering isolated hills in 2D are shown in Fig. 12. The development of the flow observed on such geometries depends largely on the presence or absence of flow separation.
The results indicated that the hill with a very gentle slope (Hill5) would cause a slight disturbance in the vertical flow, as illustrated in Fig. 12 (lines 2 \& 4).

The airflow generally takes the maximum speed near the top (Fig. 12) and decelerates on the leeward side of the hill. The boundary layer developing on the hill will differ significantly from the turbulent logarithmic boundary layer typically found on a flat plat.

As we can see in Fig. 12 (lines 1 \& 3), for a steeper hill (Hill 3), an adverse pressure gradient can lead to the separation of the flow and create a wake area on the downstream side of the hill. The separate flow region of the hill is characterized by lower flow velocities than upstream from the slopes of the hill and by more intense mixing due to the turbulent irregular vortices. A reverse flow region may also form behind the hill due to the recirculation of the flow. The shape of the hill and its local surface roughness influence the location of the flow separation. Furthermore, it is noted that the $k-\varepsilon$ turbulence model does not predict any separation in the wake of the hill that is characterized by the slight slope, the speed in the $\mathrm{x}$-direction never becomes negative as shown in Fig. 12 (line 2). Nevertheless, the SSTK - $\omega$ model produces a certain separation in Fig. 12 (line 4), but the size and length of the recirculation zone are still not predicted, which suggests faster recovery of the flow. Generally, it can be concluded that hill slopes of $16^{\circ}$ or less are unlikely to result in separation of flows, while it can most likely occur on slopes of $26^{\circ}$ or higher than this shape of the slope.

By moving the flow down the hill, the blocking effect will gradually decrease and disappear completely when the flow reaches the top. As can be seen in Fig. 12, the effect of acceleration increases continuously and reaches its maximum at the summit, more precisely for the steep slope H3. In this area, the boundary layer is disturbed and a thin layer of shear is formed.

In Fig. 13, the comparison of the turbulent kinetic energy (TKE) predictions generated by the leeward separation of the two hills are briefly illustrated. These contours show similar behavior of velocity for the two models used in this section. Otherwise, this figure indicates the degree of the concentration of the TKE in the shear layer, which separates the recirculation zone from the outer layer.

Simulation results by using the standard $k-\varepsilon$ model for the airflow over the steep slope $\mathrm{H} 3$ indicates that this model gives an underestimation of the turbulent kinetic energy with a maximum value of approximately $0.6 \mathrm{~m}^{2} / \mathrm{s}^{2}$. This means that it can be considered as a most dissipative model and includes a large length scale. On the other hand, it confirms the length of the recirculation zone presented in section 5.1. However, the SSTK - $\omega$ turbulence model presents an estimate of the significant turbulent kinetic energy that takes the maximum value of $0.94 \mathrm{~m}^{2} / \mathrm{s}^{2}$ as shown in Fig. 13 (line 3). In the same way, it implies that this model is less dissipative in comparison by the $k-\varepsilon$ model and ensures the prediction of the separation, of the reverse flow (vortex) and the recirculation region presented in section 5.1. On the other hand, the hill with a slight slope H5 (see Fig. 13 (line 2)) has a lower estimate of the TKE at the wake 


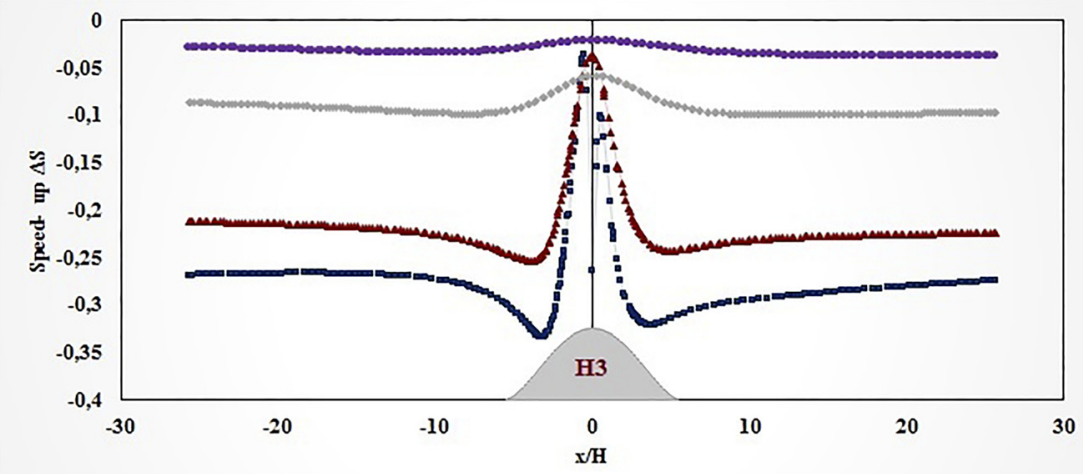

(a) Standard $k-\varepsilon \rightarrow y=1 \mathrm{H} \quad \triangle \mathrm{y}=1.17 \mathrm{H} \quad \forall \mathrm{y}=5.13 \mathrm{H} \quad \bullet \mathrm{y}=8.55 \mathrm{H}$

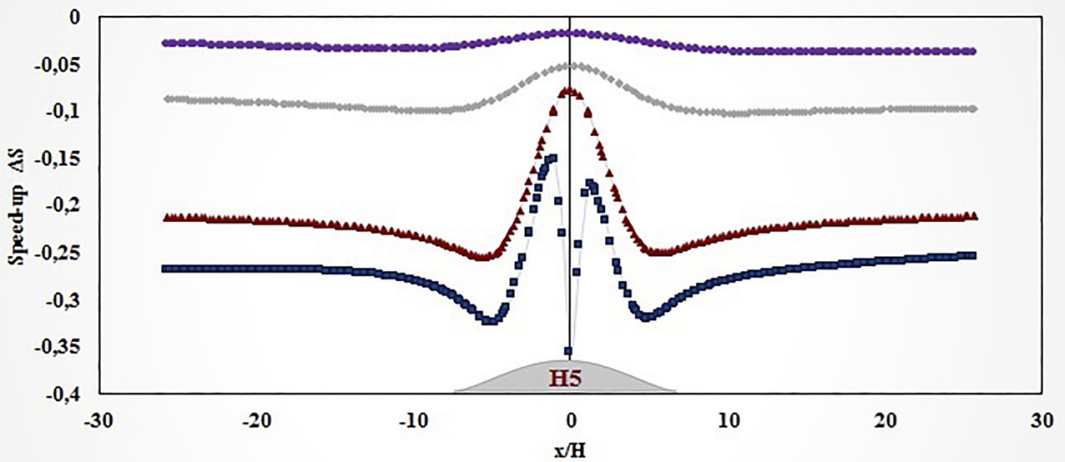

(b) Standard $k-\varepsilon \rightarrow y=1 \mathrm{H} \rightarrow \mathrm{y}=1.17 \mathrm{H} \rightarrow \mathrm{y}=5.13 \mathrm{H} \rightarrow \mathrm{y}=8.55 \mathrm{H}$

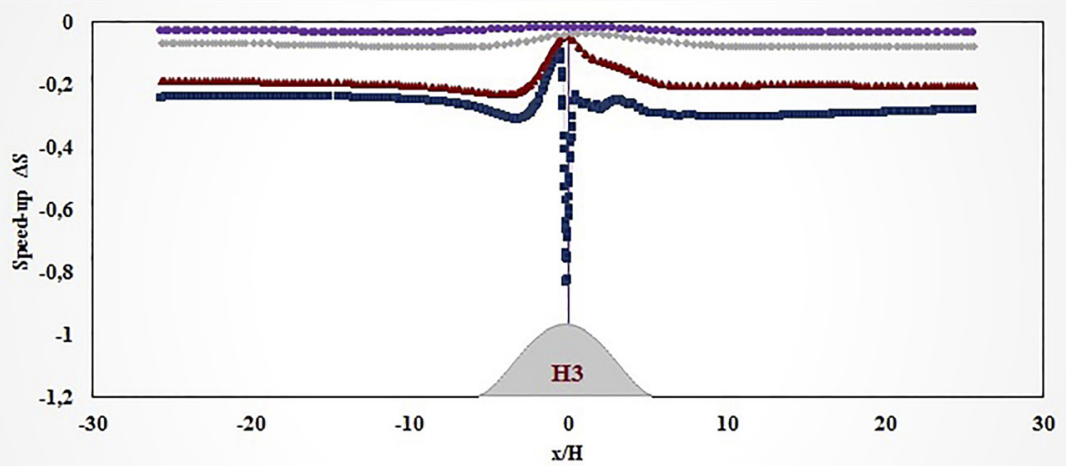

(c) $\quad \mathrm{SST} \mathrm{k-w} \backsim y=1 \mathrm{H} \rightarrow \mathrm{-}=1.17 \mathrm{H} \rightarrow \mathrm{y}=5.13 \mathrm{H} \quad-\mathrm{y}=8.55 \mathrm{H}$

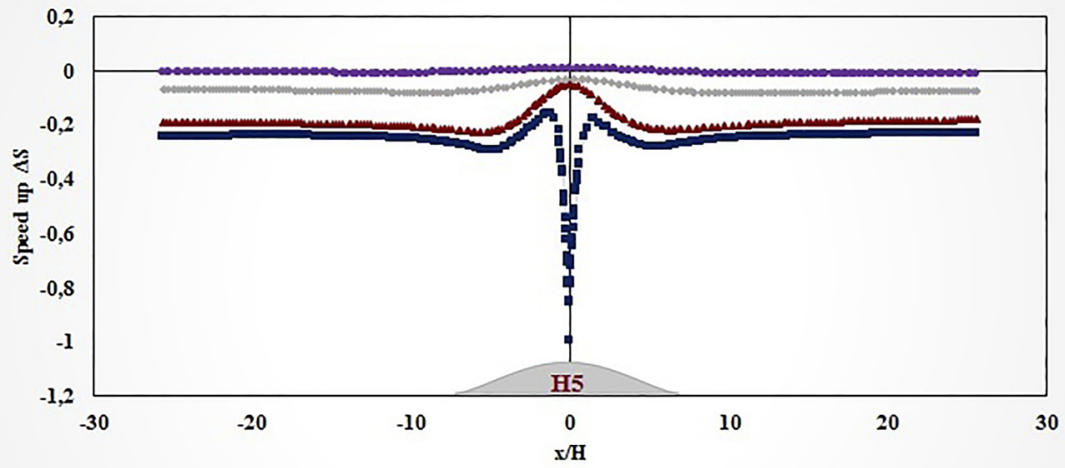

(d) SST k-w $-y=1 \mathrm{H}-\mathrm{\wedge}=1.17 \mathrm{H} \rightarrow \mathrm{y}=5.13 \mathrm{H} \rightarrow \mathrm{y}=8.55 \mathrm{H}$

Fig. 11. Speed-Up profiles in different horizontal positions over two slopes H3 (a \& c) and H5 (b \& d) 

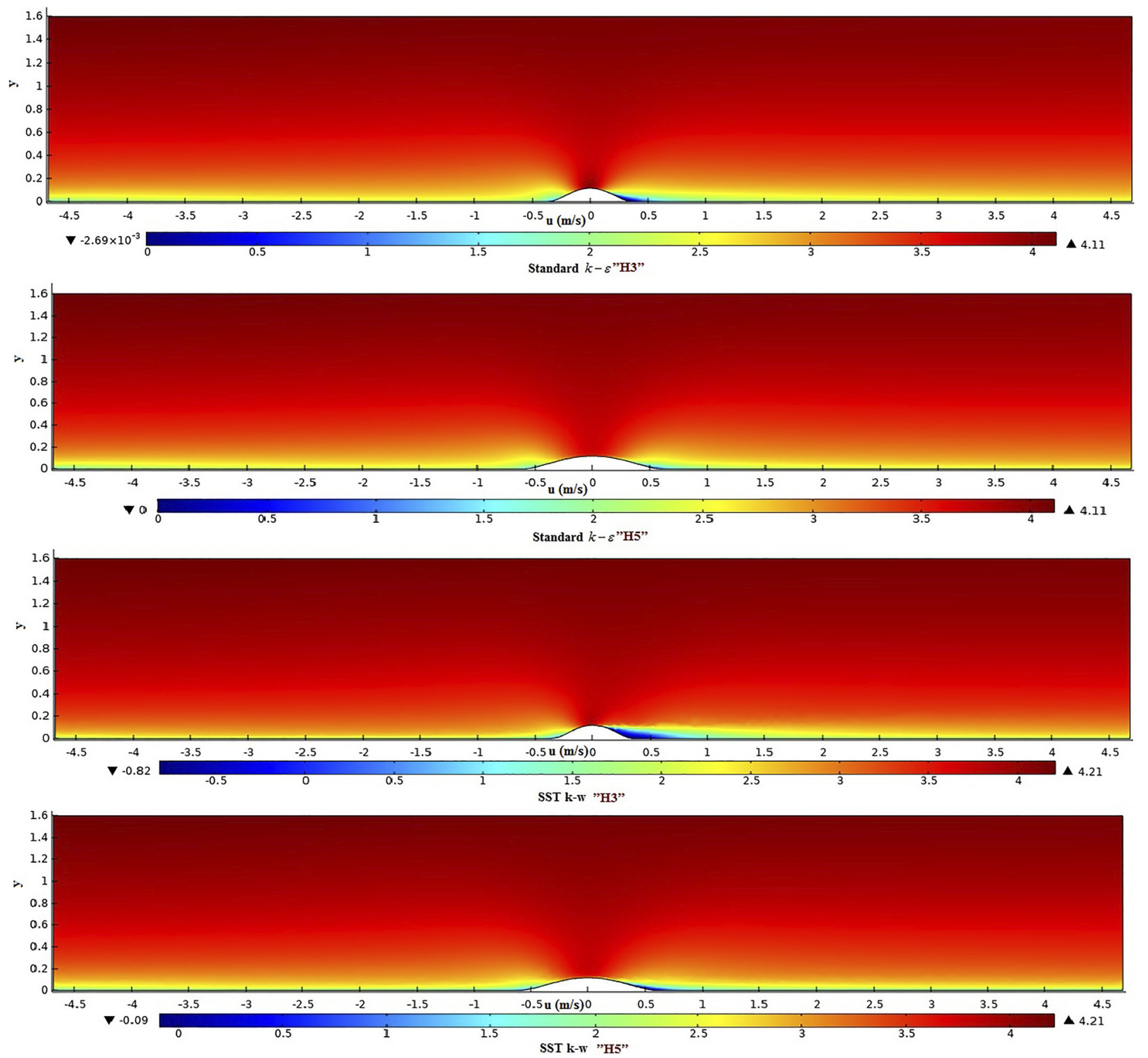

Fig. 12. Contours of the x-velocity component over two slopes H3 (line $1 \&$ line 3 ) and H5 (line $1 \&$ line 4 ) under standard $k-\varepsilon$ and SSTk $-\omega$ turbulence models

area of the hill for the $k-\varepsilon$ model and a slight estimate for the SSTk $-\omega$ model, and this ensures the ability of the model to capture this region adequately. However, an observation of the important values of the turbulent kinetic energy at the entrance of the domain until the downhill of the slope $\mathrm{H} 5$ for the same model, and this for a probable reason relies on the small size of the hill $\mathrm{H} 5$.

In general, the hill (Hill 5) is more sensitive than the hill (Hill 3) due to the lower slope and therefore the fact that the flow is at the threshold of separation. This means that small changes in the upstream boundary layer can cause separation and result a completely different flow upstream and downstream of the separation. On the other hand, the SSTK - $\omega$ turbulence model provided the best prediction of the separated region directly in the wake of the hill and showed the best correspondence with the wind tunnel measurements for the recirculation region length.

\section{CONCLUSIONS}

The paper set out to perform the two-dimensional computation of airflow over hill in complex terrain by using the commercial code COMSOL Multiphysics. The high-resolution steady-state RANS simulations are used to study the turbulence boundary layer flows over hilly terrain, also, to assess the performance of two turbulence schemes, more especially: standard $k-\varepsilon$ and SSTk $-\omega$ in neutral stratified conditions with two various near-wall treatment such as the scalable wall function (smooth) and enhanced wall treatment, respectively. The performance of these turbulence 

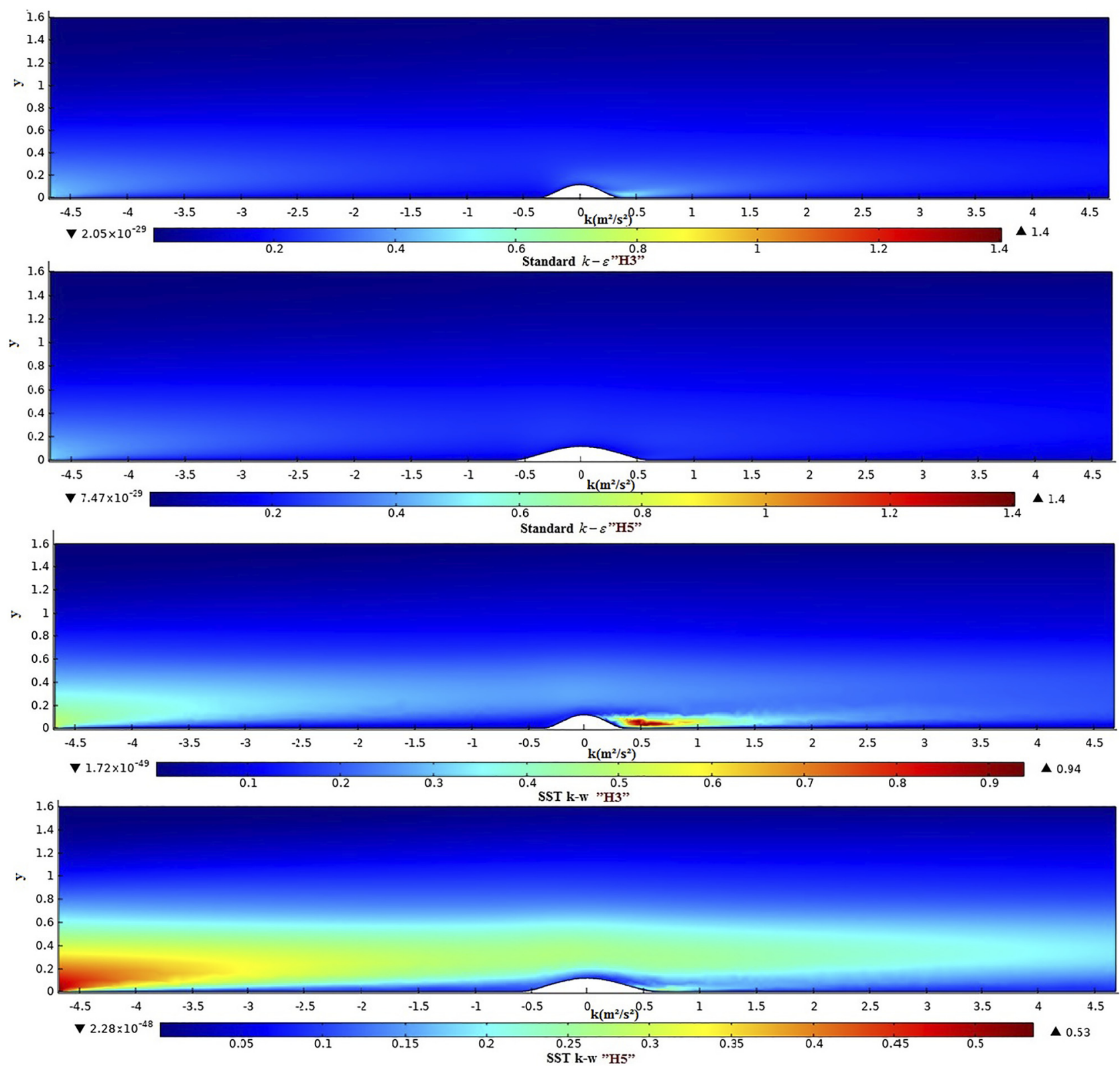

Fig. 13. Contours of the TKE distribution around two shape of slopes H3 (line $1 \&$ line 3 ) and H5 (line $2 \& 4$ ) under standard $k-\varepsilon$ and SSTK $-\omega$ turbulence model

models was studied and their predictions for the average features of the airflow were validated with an idealized $2 \mathrm{D}$ RUSHIL wind-tunnel measurement and the predicted flow fields were analyzed in terms of the variability between the different models.

The study suggests that the prediction of mean velocity is quite good at most locations and the expected reattachment length is certainly closer to the measurements than some previous studies. Therefore, the SSTK $-\omega$ turbulence model is recalibrated by using new closure coefficients in neutral conditions and turbulence parameters based on the previously published study to investigate the sensitivity of this modeling constant on the accuracy of predictions and to minimize the discrepancy of the numerical results from a set of measured data.
The results indicate overall compatible behavior for two models despite an acceptable deviation from the experimental set of data. Regarding some discrepancies between the predicted streamwise velocity profile and experimental data for three position $\mathrm{x} / \mathrm{H}=-3, \mathrm{x} / \mathrm{H}=0, \mathrm{x} / \mathrm{H}=3$, the standard $k-\varepsilon$ reproduces the exact experimental profiles at two-sensitivity region upwind and on the summit of the hill $(\mathrm{x} / \mathrm{H}=0)$. Nevertheless, it over-predicts wind speed close to the wall on the top, which requires an improvement of the near-wall treatment by using rough surface conditions. Furthermore, the model gives less accurate results at downwind of the hill $\mathrm{x} / \mathrm{H}=3$ when compared by further turbulence models in the same condition. On the other hand, the SSTK $-\omega$ model in neutral ABL condition provided more adequate results in most positions, in terms of 
physics and from experimental measurement validation, in comparison to the case of using the standard coefficients of the model, precisely on the most sensitive separation region. This is due to the capacity of the model and to the performance of the new closures coefficients adjusted for this model under neutral boundary layer conditions, which allowed the level of turbulence to be captured more accurately.

The results of CFD simulation in the case study of the impact of hilly configurations on two different slopes have briefly been presented in this work. It should be remarked that modeling complex flow regions, such as recirculation zones, the SSTK - $\omega$ model has proven to be the most accurate model for any degree of hill slope when compared by the measurement data. Although the standard $k-\varepsilon$ model is designed specifically for the acceleration regions and the windward side for the hill compared by the experiment, it is unsuitable in the separation region for the gentle slope case. Therefore, in future works, the CFD simulation of the airflow with a steady 2D RANS approach with rough wall function will be performed for the purpose to simulate the impact of the roughness on the flow characteristic because most topography surfaces are rough.

Next, we have shifted our attention to the case of the hill slope effect on the mean velocity and turbulence. The main findings of this study can be summarized as follows:

1. Hill slopes are an important element for the flow characteristics affect. The steep slope, the separation of the flow due to the high adverse pressure gradient will considerably decrease the average speed, which can provide a negative effect on the energy potential of wind turbines.

2. In the crest of the hill, it shows that the shape of the slope has an important effect on the prediction of speed acceleration (speed-up) at the top of the hill. It remarks that the average speed highly increases for the steep slope compared by a gentle slope, which can lead to an extractable maximum power rate of the wind turbine.

3. The velocity profile at the foot of the hill is still higher for the low slope due to the small effect of the separation than the high slope. Therefore, it can produce a positive effect on wind speed in this region.

\section{NOMENCLATURE}

\section{a Half-length}

$C_{p} \quad$ Pressure coefficient

$D \quad$ Depth of the boundary layer

$H \quad$ Height of the hill

$k \quad$ Turbulent kinetic energy

$R_{e} \quad$ Reynolds number

$S_{\varphi} \quad$ Sources terms

$t \quad$ Time

$u_{j} \quad$ Velocity component

$U_{0} \quad$ Free stream velocity

$u_{*} \quad$ Friction velocity $x_{j} \quad$ Cartesian coordinate

$z_{0} \quad$ Roughness length

$\kappa \quad$ Von Karman's constant

$\varphi \quad$ variables

$\mu \& \mu_{t} \quad$ Dynamic viscosity and turbulent viscosity

$\nu_{t} \quad$ Turbulent kinematic viscosity

$\Gamma_{\varphi, e f f} \quad$ Effective diffusion coefficient

$\rho \quad$ Air density

$\delta \quad$ Distance from the wall

$\delta^{+} \quad$ Wall normal coordinate

\section{ABBREVIATION}

ABL Atmospheric Boundary Layer

CFD Computational Fluid Dynamics

FEM Finite Element Method

RANS Reynolds Averaged Navier-Stokes

\section{REFERENCES}

[1] P. H. Alfredsson, and A. Segalini, "Introduction Wind farms in complex terrains: an introduction," Philos. Trans. A. Math. Phys. Eng. Sci., vol. 375, no. 2091, Apr. 2017.

[2] A. F. P. Ribeiro, A. M. Awruch, and H. M. Gomes, "An airfoil optimization technique for wind turbines," Appl. Math. Model., vol. 36, no. 10, pp. 4898-907, Oct. 2012.

[3] M. Sessarego, W. Shen, M. van der Laan, K. Hansen, W. Zhu, M. Sessarego, W. Z. Shen, M. P. Van der Laan, K. S. Hansen, and W. J. Zhu, "CFD simulations of flows in a wind farm in complex terrain and comparisons to measurements," Appl. Sci., vol. 8, no. 5, p. 788, May 2018.

[4] W. Tian, A. Ozbay, and H. Hu, Terrain Effects on Characteristics of Surface Wind and Wind Turbine Wakes, vol. 126. Elsevier B.V., 2015.

[5] A. Narjisse, and K. Abdellatif, "Analysis of obstacle and soil roughness effects on the wind speed profile by using the finite element method," Proced. Eng., vol. 181, 2017.

[6] J. H. Ferziger, and M. Peric, Computational Methods for Fluid Dynamics, 3rd ed. Stanfrod, USA: Springer, 2002.

[7] S. Iizuka, and H. Kondo, "Large-eddy simulations of turbulent flow over complex terrain using modified static eddy viscosity models," Atmos. Environ., vol. 40, no. 5, pp. 925-35, Feb. 2006.

[8] M. Balogh, A. Parente, and C. Benocci, "RANS simulation of ABL flow over complex terrains applying an Enhanced k- $\varepsilon$ model and wall function formulation: Implementation and comparison for fluent and OpenFOAM," J. Wind Eng. Ind. Aerodyn., vol. 104106, pp. 360-8, May 2012.

[9] M. Pontiggia, M. Derudi, V. Busini, and R. Rota, "Hazardous gas dispersion: A CFD model accounting for atmospheric stability classes," J. Hazard. Mater., vol. 171, no. 1-3, pp. 739-47, 2009.

[10] A. Parente, R. Longo, M. Ferrarotti, and P. Milano, CFD Boundary Conditions, Turbulence Models and Dispersion Study for Flows Around Obstacles. Italy: Université Libre de Bruxelles, 2017. 
[11] I. Bouras, L. Ma, D. Ingham, and M. Pourkashanian, "An improved $\mathrm{k}-\omega$ turbulence model for the simulations of the wind turbine wakes in a neutral atmospheric boundary layer flow," $J$. Wind Eng. Ind. Aerodyn., vol. 179, no. May, pp. 358-68, 2018.

[12] B. Blocken, J. Carmeliet, and T. Stathopoulos, "CFD evaluation of wind speed conditions in passages between parallel buildings-effect of wall-function roughness modifications for the atmospheric boundary layer flow," J. Wind Eng. Ind. Aerodyn., vol. 95, no. 911, pp. 941-62, 2007.

[13] P. S. Jackson, and J. C. R. Hunt, "Turbulent wind flow over a low hill," Q. J. R. Meteorol. Soc., vol. 101, no. 430, pp. 929-55, 1975.

[14] P. Carpenter, and N. Locke, "Investigation of wind speeds over multiple two-dimensional hills," J. Wind Eng. Ind. Aerodyn., vol. 83, no. 1-3, pp. 109-20, 1999.

[15] S. J. Lee, H. C. Lim, and K. C. Park, "Wind flow over sinusoidal hilly obstacles located in a uniform flow," Wind Struct. Int. J., vol. 5, no. 6, pp. 515-26, 2002.

[16] T. Ishihara, and K. Hibi, "Numerical study of turbulent wake flow behind a three-dimensional steep hill," Wind Struct., vol. 5, no. 2_3_4, pp. 317-28, Apr. 2002.

[17] F. A. Castro, J. M. L. M. Palma, and A. Silva Lopes, "Simulation of the Askervein flow. Part 1: Reynolds averaged Navier-Stokes equations (k-epsilon turbulence model)," Boundary-Layer Meteorol., vol. 107, no. 3, pp. 501-30, Jun. 2003.

[18] J. Chung, and B. Bienkiewicz, "Numerical simulation of flow past 2D hill and valley," Wind Struct., vol. 7, no. 1, pp. 1-12, Feb. 2004.

[19] Stangroom.P, "CFD modelling of wind flow over terrain", $\mathrm{PhD}$ thesis, University of Nottingham, 2004.

[20] G. T. Bitsuamlak, T. Stathopoulos, and C. Bédard, "Numerical evaluation of wind flow over complex terrain: Review," J. Aerosp. Eng., vol. 17, no. 4, pp. 135-45, Oct. 2004.

[21] S. Cao, T. Wang, Y. Ge, and Y. Tamura, "Numerical study on turbulent boundary layers over two-dimensional hills - effects of surface roughness and slope," Wind Eng. Ind. Aerodyn., vol. 104106, pp. 342-9, 2012.

[22] A. Rasouli, and H. Hangan, "Microscale computational fluid dynamics simulation for wind mapping over complex topographic terrains," J. Sol. Energy Eng., vol. 135, no. 4, p. 041005, Jun. 2013.

[23] M. F. Yassin, M. Al-Harbi, and M. A. Kassem, "Computational fluid dynamics (CFD) simulations on the effect of rough surface on atmospheric turbulence flow above hilly terrain shapes," Environ. Forensics, vol. 15, no. 2, pp. 159-74, 2014.

[24] V. Chitta, T. Jamal, and D. Keith Walters, "Computational Fluid Dynamics study of separated flow over a three-dimensional axisymmetric hill," J. Fluids Eng., vol. 141, no. 1, p. 011205, Jun. 2018.

[25] A. Bechmann, "Large-eddy simulation of atmospheric flow over complex terrain," 2006.

[26] A. Chaudhari, A. Hellsten, O. Agafonova, and J. Hämäläinen, "Large eddy simulation of boundary-layer flows over twodimensional hills," Springer, Cham, 2014, pp. 211-8.

[27] S. Kenjeres, "Some developments in turbulence modeling for wind and environmental engineering," vol. 96, pp. 1537-70, 2008.

[28] C. Gacherieu, and C. Weber, "Assessment of algebraic and oneequation turbulence models for transonic turbulent flow around a full aircraft configuration," AIAA Pap., vol. 98-32457, pp. 619-29, 1998.

[29] Č. Kostić, "Review of the Spalart-Allmaras turbulence model and its modifications to three-dimensional supersonic configurations," Sci. Tech. Rev., vol. 65, no. 1, pp. 43-9, 2015.
[30] Y. Cheng, F. S. Lien, E. Yee, and R. Sinclair, "A comparison of large Eddy simulations with a standard k- $\varepsilon$ Reynolds-averaged Navier-Stokes model for the prediction of a fully developed turbulent flow over a matrix of cubes," J. Wind Eng. Ind. Aerodyn., vol. 91, no. 11, pp. 1301-28, 2003.

[31] J. Van Beeck, and C. Benocci, "Improved k - epsilon model and wall function formulation for the RANS simulation of ABL flows," J. Wind Eng. Ind. Aerodyn., vol. 99, pp. 267-78, 2011.

[32] A. Sogachev, M. Kelly, and M. Y. Leclerc, "Consistent two-equation closure modelling for atmospheric research: Buoyancy and vegetation implementations," Boundary-Layer Meteorol., vol. 145, no. 2, pp. 307-27, 2012.

[33] P. Hu, Y. Li, C. S. Cai, H. Liao, and G. J. Xu, "Numerical simulation of the neutral equilibrium atmospheric boundary layer using the SST k- $\omega$ turbulence model," Wind Struct., vol. 17, no. 1, pp. 87-105, Jul. 2013.

[34] D. S. Abdi, and G. T. Bitsuamlak, "Wind flow simulations on idealized and real complex terrain using various turbulence models," Adv. Eng. Softw., vol. 75, pp. 30-41, Sep. 2014.

[35] J. B. R. Loureiro, A. T. P. Alho, and A. P. Silva Freire, "The numerical computation of near-wall turbulent flow over a steep hill," J. Wind Eng. Ind. Aerodyn., vol. 96, no. 5, pp. 540-61, 2008.

[36] S. Yan, S. Shi, X. Chen, X. Wang, L. Mao, and X. Liu, "Numerical simulations of flow interactions between steep hill terrain and large scale wind turbine," Energy, vol. 151, pp. 740-7, 2018.

[37] T. Uchida, "Reproducibility of complex turbulent flow using commercially-available CFD software," Rep. Res. Inst. Appl. Mech. Kyushu Univ., vol. 150, no. 150, pp. 47-59, 2016.

[38] H.A. Panofsky, and J.A. Dutton, Atmospheric Turbulence: Models and Methods for Engineering Applications, 1st ed. New York: John Wiley, 1984.

[39] E. G. A. Antonini, D. A. Romero, and C. H. Amon, "Analysis and modifications of turbulence models for wind turbine wake simulations in atmospheric boundary layers," vol. 140, no. June, pp. $1-13,2018$.

[40] D. M. Hargreaves, and N. G. Wright, "On the use of the k-epsilon model in commercial CFD software to model the neutral atmospheric boundary layer," J. Wind Eng. Ind. Aerodyn., vol. 95, pp. 355-69, 2007.

[41] F. Juretic, and H. Kozmar, "Computational modeling of the neutrally stratified atmospheric boundary layer flow using the standard k - e turbulence model," Int. J. Wind Eng. Ind. Aerodyn., vol. 115, pp. 112-20, 2013.

[42] W. Yang, Y. Quan, X. Jin, Y. Tamura, and M. Gu, "Influences of equilibrium atmosphere boundary layer and turbulence parameter on wind loads of low-rise buildings," vol. 96, pp. 2080-92, 2008.

[43] Y. Yang, Z. Xie, and M. Gu, "Consistent inflow boundary conditions for modelling the neutral equilibrium atmospheric boundary layer for the SST k- $\omega$ model," Wind Struct., vol. 24, no. 5, pp. 465-80, May 2017.

[44] D. Kuzmin, "A guide to numerical methods for transport equations," Friedrich-Alexander-Universitat Erlangen-nurnb., pp. 5-8, 2010.

[45] COMSOL, Guide COMSOL: Introduction to COMSOL Multiphysics. Sweden, 2016.

[46] L. H. Khurshudyan, Flow and Dispersion of Pollutants over TwoDimensional Hills: Summary Report on Joint Soviet-American 
Study/Leon H. Khurshudyan, William H. Snyder, and Igor V. Nekrasov. - Version details - Trove. United States, 1982.

[47] H.K. Versteeg, and W. Malalasekera, An Introduction to Computational Fluid Dynamics, 1 ed. New York: Longman, 1995.

[48] J. Boussinesq, Essai sur la théorie des eaux courantes. Hachette Livre - BNF, 1877.

[49] D. J. Tritton, Physical Fluid Dynamics. Dordrecht: Springer Netherlands, 1977.

[50] W. Jones, and B. Launder, "The prediction of laminarization with a two-equation model of turbulence," Int. J. Heat Mass Transf., vol. 15, no. 2, pp. 301-14, Feb. 1972.

[51] B. E. Launder, and B. I. Sharma, "Application of the energydissipation model of turbulence to the calculation of flow near a spinning disc," Lett. Heat Mass Transf., vol. 1, no. 2, pp. 131-7, Nov. 1974.

[52] S. B. Pope, Turbulent Flows. Cambridge: Cambridge University Press, 2000.

[53] H.A. Panofsky, and J.A. Dutton, Atmospheric Turbulence. Models and Methods for Engineering Applications, First edit. New York, 1984.

[54] D. C. Wilcox, "Turbulence modeling for CFD," DCW Industries, 1998.

[55] F. R. Menter, "Two-equation eddy-viscosity turbulence models for engineering applications," AIAA J., vol. 32, no. 8, pp. 1598-605, Aug. 1994.

[56] Y. Yang, M. Gu, S. Chen, and X. Jin, "New inflow boundary conditions for modelling the neutral equilibrium atmospheric boundary layer in computational wind engineering," J. Wind Eng. Ind. Aerodyn., vol. 97, no. 2, pp. 88-95, Feb. 2009.
[57] Olaf Schenk, and K. Gaerter, Parallel Sparse Direct Solver (PARDISO), User Guide Version 6.0.0. 2018.

[58] I. P. Castro and D. D. Apsley, "Flow and dispersion over topography: a comparison between numerical and laboratory data for two-dimensional flows," Atmos. Environ., vol. 31, no. 6, pp. 839-50, Mar. 1997.

[59] P. J. Richards and R. P. Hoxey, "Appropriate boundary conditions for computational wind engineering models using the $\mathrm{k}-\varepsilon$ turbulence model," J. Wind Eng. Ind. Aerodyn., vol. 46-47, no. C, pp. 145-53, 1993.

[60] D. Kuzmin, O. Mierka, and S. Turek, "On the implementation of the $\kappa-\varepsilon$ turbulence model in incompressible flow solvers based on a finite element discretisation," Int. J. Comput. Sci. Math., vol. 1, no. 2/3/4, p. 193, 2007.

[61] H. Grotjans and F. Menter, "Wall functions for general application CFD codes,” ECCOMAS'98, vol. 1, pp. 1112-7, 1998.

[62] W. Lubitz and B. R. White, "Wind-tunnel and field investigation of the effect of local wind direction on speed-up over hills," $J$. Wind Eng. Ind. Aerodyn., vol. 95, pp. 639-61, 2007.

[63] D. R. Webster, D. B. Degraaff, and J. K. Eaton, "Turbulence characteristics of a boundary layer over a two-dimensional bump," J. Fluid Mech., vol. 320, no. 1, p. 53, Aug. 1996.

[64] J. C. R. Hunt and W. H. Snyder, "Experiments on stably and neutrally stratified flow over a model three-dimensional hill," $J$. Fluid Mech., vol. 96, no. 04, p. 671, Feb. 1980.

[65] E. S. Politis, J. Prospathopoulos, D. Cabezon, K. S. Hansen, P. K. Chaviaropoulos, and R. J. Barthelmie, "Modeling wake effects in large wind farms in complex terrain: the problem, the methods and the issues," Wind Energy, vol. 15, no. 1, pp. 161-82, Jan. 2012. 